\title{
Solid Hydrogen Experiments for Atomic Propellants: Particle Formation, Imaging, Observations, and Analyses
}

Bryan Palaszewski

Glenn Research Center, Cleveland, Ohio 
Since its founding, NASA has been dedicated to the advancement of aeronautics and space science. The NASA Scientific and Technical Information (STI) Program Office plays a key part in helping NASA maintain this important role.

The NASA STI Program Office is operated by Langley Research Center, the Lead Center for NASA's scientific and technical information. The NASA STI Program Office provides access to the NASA STI Database, the largest collection of aeronautical and space science STI in the world. The Program Office is also NASA's institutional mechanism for disseminating the results of its research and development activities. These results are published by NASA in the NASA STI Report Series, which includes the following report types:

- $\quad$ TECHNICAL PUBLICATION. Reports of completed research or a major significant phase of research that present the results of NASA programs and include extensive data or theoretical analysis. Includes compilations of significant scientific and technical data and information deemed to be of continuing reference value. NASA's counterpart of peerreviewed formal professional papers but has less stringent limitations on manuscript length and extent of graphic presentations.

- TECHNICAL MEMORANDUM. Scientific and technical findings that are preliminary or of specialized interest, e.g., quick release reports, working papers, and bibliographies that contain minimal annotation. Does not contain extensive analysis.

- CONTRACTOR REPORT. Scientific and technical findings by NASA-sponsored contractors and grantees.
- CONFERENCE PUBLICATION. Collected papers from scientific and technical conferences, symposia, seminars, or other meetings sponsored or cosponsored by NASA.

- SPECIAL PUBLICATION. Scientific, technical, or historical information from NASA programs, projects, and missions, often concerned with subjects having substantial public interest.

- TECHNICAL TRANSLATION. Englishlanguage translations of foreign scientific and technical material pertinent to NASA's mission.

Specialized services that complement the STI Program Office's diverse offerings include creating custom thesauri, building customized databases, organizing and publishing research results ... even providing videos.

For more information about the NASA STI Program Office, see the following:

- Access the NASA STI Program Home Page at http://www.sti.nasa.gov

- E-mail your question via the Internet to help@sti.nasa.gov

- Fax your question to the NASA Access Help Desk at 301-621-0134

- Telephone the NASA Access Help Desk at 301-621-0390

- Write to:

NASA Access Help Desk

NASA Center for AeroSpace Information 7121 Standard Drive

Hanover, MD 21076 
NASA/TM-2005-212897

\section{Solid Hydrogen Experiments for Atomic Propellants: Particle Formation, Imaging, Observations, and Analyses}

Bryan Palaszewski

Glenn Research Center, Cleveland, Ohio

Prepared for the

39th Joint Propulsion Conference and Exhibit

cosponsored by the AIAA, ASME, SAE, and ASEE

Huntsville, Alabama, July 20-23, 2003

National Aeronautics and

Space Administration

Glenn Research Center 


\section{Acknowledgments}

I'd like to thank the people who assisted in the construction and execution of the experiments conducted at NASA Glenn Research Center: Maureen Kudlac (GL), Henry Speier, Joan Hoopes, Ernie Bell, Donald Metcalf, and Robert Vanek. Thanks to Hugh Aylward for the image capturing and pixel measurements of the particle sizes.

Thanks to Brienne Curley (of the University of Toledo) for her assistance with data extraction and plotting. I'd also like to thank John Cole, head of Space Transportation Research (STR) aspects of the NASA Advanced Space Transportation Program (ASTP), led by NASA Marshall Space Flight Center. Extensive cooperation with the U.S. Air Force Research Laboratory (Edwards, CA) was also a critical part of this testing.

Available from

NASA Center for Aerospace Information 7121 Standard Drive

Hanover, MD 21076
National Technical Information Service 5285 Port Royal Road Springfield, VA 22100

Available electronically at http:/ /gltrs.grc.nasa.gov 


\title{
Solid Hydrogen Experiments for Atomic Propellants: Particle Formation, Imaging, Observations, and Analyses
}

\author{
Bryan Palaszewski \\ National Aeronautics and Space Administration \\ Glenn Research Center \\ Cleveland, Ohio 44135
}

\begin{abstract}
Summary
This report presents particle formation observations and detailed analyses of the images from experiments that were conducted on the formation of solid hydrogen particles in liquid helium. Hydrogen was frozen into particles in liquid helium, and observed with a video camera. The solid hydrogen particle sizes and the total mass of hydrogen particles were estimated. These newly analyzed data are from the test series held on February 28, 2001. Particle sizes from previous testing in 1999 and the testing in 2001 were similar. Though the 2001 testing created similar particles sizes, many new particle formation phenomena were observed: microparticles and delayed particle formation. These experiment image analyses are some of the first steps toward visually characterizing these particles, and they allow designers to understand what issues must be addressed in atomic propellant feed system designs for future aerospace vehicles.
\end{abstract}

\section{Introduction}

For over 70 years, the promise of atomic propellants has been investigated (refs. 1 to 35). Using atoms of boron, carbon, or hydrogen, maintained at cryogenic temperatures, very exciting advances in rocket propellants and airbreathing fuels can be realized. Atomic propellants are composed of atomic species stored in a large number of cryogenic solid molecular hydrogen particles. These particles are stored in liquid helium to prevent the recombination of the atoms into molecules. Once the hydrogen is warmed as it flows, and the atoms are allowed to recombine, the recombination energy heats the hydrogen and helium to high temperatures, and the resulting gases can be directed in a traditional convergingdiverging nozzle to create thrust and, theoretically, high specific impulse (refs. 1 to 6).

Over the decades, many details of the physics of storing such propellants have been analyzed and experimentally determined. Current research is underway with a team from the U.S. Air Force, NASA, the Department of Energy, university, industry, and small business partners (ref. 7). The extensive data that have been amassed over many decades have shown increasing storage densities for atoms in solid cryogenic storage media and that there may be future breakthroughs that allow more routine use of atoms for fuels.

Characterizing solid hydrogen particles is required before any practical propellant feed system can be created. Solid hydrogen particles were selected as a means of storing atomic propellants in future launch vehicles (ref. 8). When storing atoms of boron, carbon, hydrogen, or other atomic materials, a solid hydrogen particle is preferred (ref. 8). Very low temperature $(<4 \mathrm{~K})$ cryogenic particles have the ability to control the atoms' lifetimes and prevent them from recombining. The particles and the atoms must remain at this low temperature until the fuel is introduced into the engine combustion (or recombination) chamber. 


\section{Why Atomic Propellants?}

In the future, rocket and airbreathing propulsion systems may be able to gain great benefits from the enormous power of atomic propellants. A summary of atomic hydrogen rocket gross lift-off weight (GLOW) is shown in figure 1 (ref. 1). Using a $15 \mathrm{wt} \%$ atomic hydrogen fuel, the GLOW of the launch vehicle can be reduced by 50 percent over the National Launch System (NLS) that uses oxygen/hydrogen $\left(\mathrm{O}_{2} / \mathrm{H}_{2}\right)$ propellants. Reductions in GLOW can also be translated into significantly increased payload capacity (refs. 1 to 8 ). The baseline rocket and payload weight for the comparison is an $\mathrm{O}_{2} / \mathrm{H}_{2}$ rocket taking $96000 \mathrm{~kg}$ of payload to Earth orbit. For the atomic hydrogen fuel, the oxidizer to fuel $(\mathrm{O} / \mathrm{F})$ ratio is 0.0 , using the fuel as a monopropellant. Additional analyses and suggested optimal fuel selections for atomic rocket vehicles are presented in references 1 to 6.

\section{Solid Hydrogen Experiments}

Solid hydrogen particle formation in liquid helium was experimentally investigated. Experiments were planned to visually characterize the particles, estimate their masses, and estimate their production efficiency. The particle sizes were estimated from video image analyses, similar to those presented in references 9 to 11. The work presented here is the detailed analyses of the Phase II (2001) video images, which precisely measured the hydrogen particle sizes. The Phase II testing of 2001 was done to improve the visualization of the particles over the previous Phase I tests performed in 1999 (refs. 3, 4, and 9). Estimates of the solid hydrogen particle sizes were made. Using the particle size analyses and Dewar gas outflow data, a solid hydrogen production efficiency was estimated.

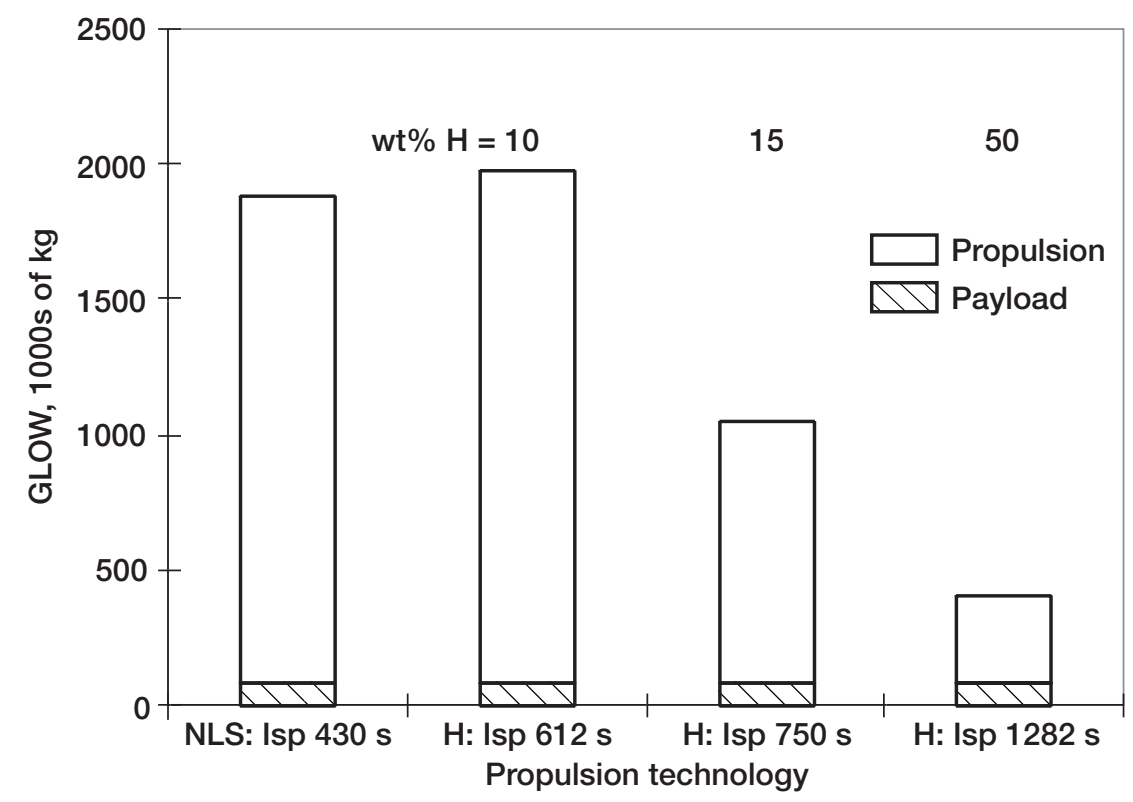

Figure 1.-Atomic hydrogen gross lift-off weight (GLOW) for monopropellants 10-, 15-, and 50-wt\% H (no He added) compared with National Launch System (NLS) using $\mathrm{O}_{2} / \mathrm{H}_{2}$ propellants. Payload for all vehicles is $96000 \mathrm{~kg}$. Isp is specific impulse. 


\section{Nomenclature}

$\begin{array}{ll}\text { ASTP } & \text { Advanced Space Transportation Program } \\ \text { FCC } & \begin{array}{l}\text { face-centered cubic } \\ \text { field of view }\end{array} \\ \text { FOV } & \text { gross lift-off weight } \\ \text { GLOW } & \text { atomic hydrogen } \\ \text { H } & \text { hexagonal close packed } \\ \text { HCP } & \text { molecular hydrogen } \\ \mathrm{H}_{2} & \text { helium } \\ \mathrm{He} & \text { National Aeronautics and Space Administration } \\ L & \text { National Launch System } \\ \text { NASA } & \text { oxidizer-to-fuel ratio } \\ \text { NLS } & \text { Small Multipurpose Research Facility } \\ \text { O/F } & \text { Space Transportation Research } \\ \text { SMIRF } & \text { weight percent } \\ \text { STR } & \text { distance of He free surface from Dewar lid } \\ \text { wt } \% & \text { nondimensional distance of He free surface from Dewar lid } \\ x & \end{array}$

\section{Solid Hydrogen Experiments}

The experiments were conducted in the Small Multipurpose Research Facility (SMIRF, formerly the Small Multilayer Insulation Research Facility, ref. 12). The facility has a vacuum tank, into which the experimental setup was placed. The vacuum tank prevented heat leaks into the Dewar and the subsequent boiloff of the liquid helium. The supporting systems (vacuum, purge, and other systems) maintain the temperature and pressure of the liquid helium bath where the solid hydrogen particles were created.

The experimental setup included several key components. A small cryogenic Dewar was used to contain the helium bath in which the solid hydrogen particles were formed. Figure 2 depicts the helium Dewar and the associated liquid hydrogen tank. The Dewar was $0.7112 \mathrm{~m}(28 \mathrm{in}$.) in height, with a $0.6096 \mathrm{~m}$ (24 in.) inside depth, and had an inside diameter of $0.3159 \mathrm{~m}$ (12.438 in.). The solid hydrogen was created from liquid hydrogen at a temperature of 14 to $18 \mathrm{~K}$. To contain the liquid hydrogen, a small stainless steel tank was used, which was $0.1524 \mathrm{~m}$ (6 in.) in diameter, and $0.6096 \mathrm{~m}$ (24 in.) long. As shown in figure 2, the tank was mounted above the Dewar. To control the hydrogen flow, a precision flow valve was used, and a video camera recorded the particle formation. All flow control for the liquid hydrogen, liquid and gaseous helium, and nitrogen purge gases was provided by the SMIRF systems.

The field of view (FOV) of the camera versus the distance from the Dewar lid was computed. All distances in the Dewar are related to distance from the Dewar lid. Figure 3 compares the camera FOV with the Dewar diameter. Once the liquid helium's free surface is at $x / L=0.43$, where the distance from the Dewar lid $x=0.3159 \mathrm{~m}$ (12.0 in.) and the depth of the Dewar $L=0.7112 \mathrm{~m}$ (28 in.), the liquid's entire surface is in the FOV. For runs, the helium liquid level was maintained at nearly 0.3556 to $0.4064 \mathrm{~m}$ (14 to 16 in.) from the Dewar lid. This location was chosen based on the knowledge of the camera FOV, and the need to observe as much of the liquid surface as possible.

Table I shows the locations of the silicon diodes for the temperature measurements. These temperature measurements were used to establish the location of the helium surface and overall image sizes and FOV. As soon as the diode temperature was seen to be above $4 \mathrm{~K}$, the liquid level was assumed to be at or near that location in the Dewar. 


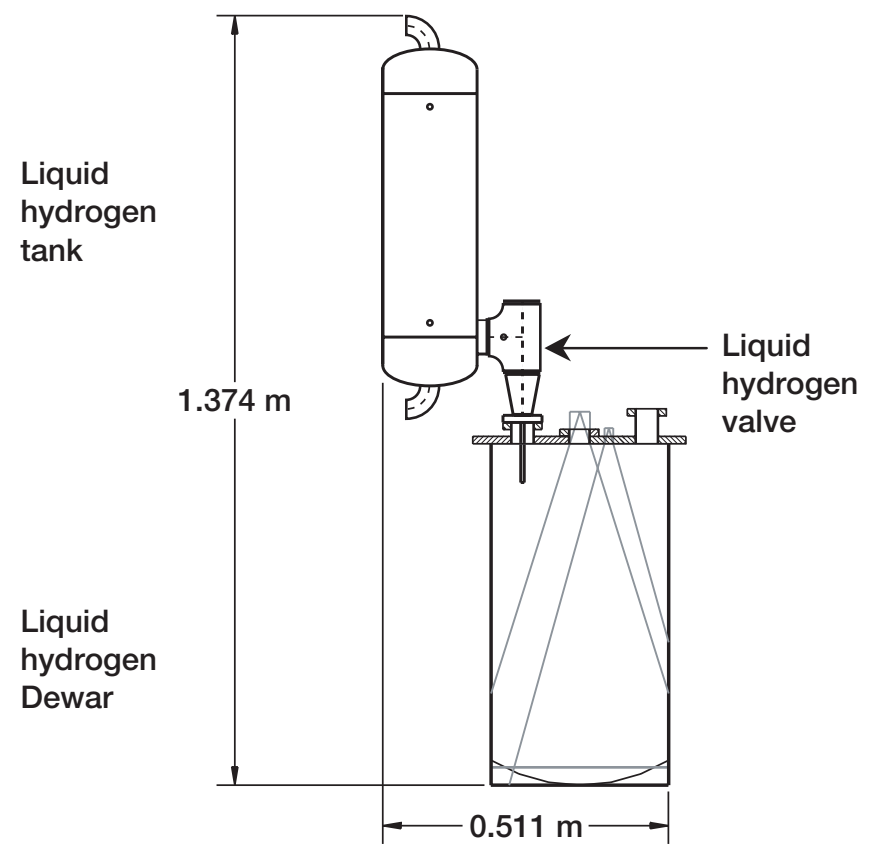

Figure 2.-Helium Dewar and liquid hydrogen tank arrangement for solid hydrogen tests.

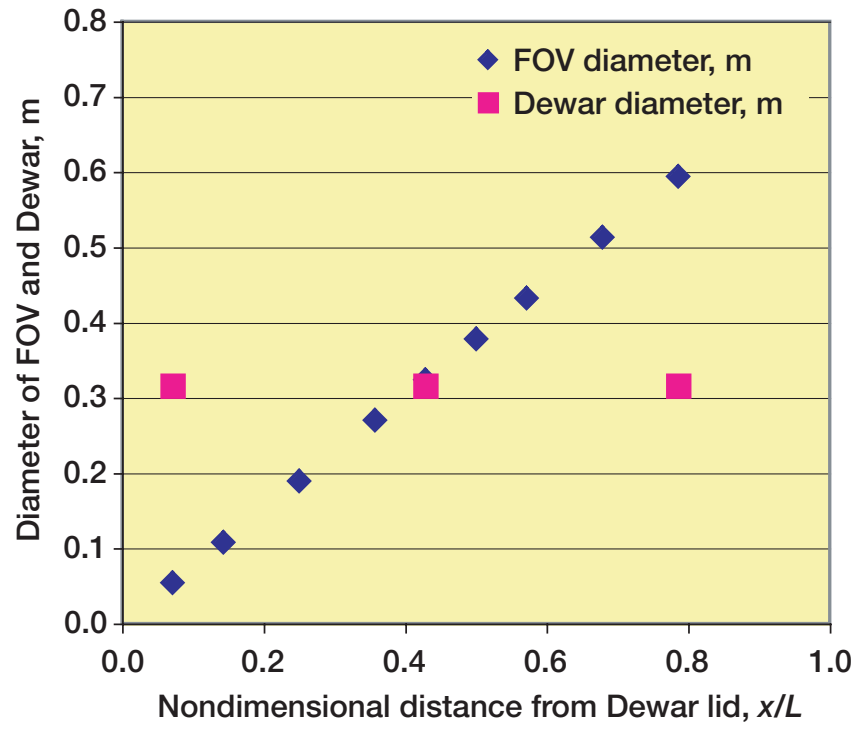

Figure 3.-Camera field of view (FOV) in solid hydrogen experiments, $28^{\circ}$ half angle. Dewar diameter is $0.3159 \mathrm{~m}$ and length $L$ is $0.7112 \mathrm{~m}$. Distance of He free surface from Dewar lid is $x$. 
Table I.-Silicon diode locations in helium Dewar [Depth of Dewar $L$ is $711.2 \mathrm{~mm}$ (28 in.).]

\begin{tabular}{|c|c|}
\hline Name & $\begin{array}{c}\text { Location below Dewar lid, } \\
\text { mm (in.) }\end{array}$ \\
\hline SD4 & $0.0(0)$ \\
LL1 & $50.8(2)$ \\
LL2 & $101.6(4)$ \\
LL3 & $177.8(7)$ \\
LL4 & $254.0(10)$ \\
& \\
LL5 & $304.8(12)$ \\
LL6 & $355.6(14)$ \\
LL7 & $406.4(16)$ \\
LL8 & $482.6(19)$ \\
LL9 & $558.8(22)$ \\
\hline
\end{tabular}

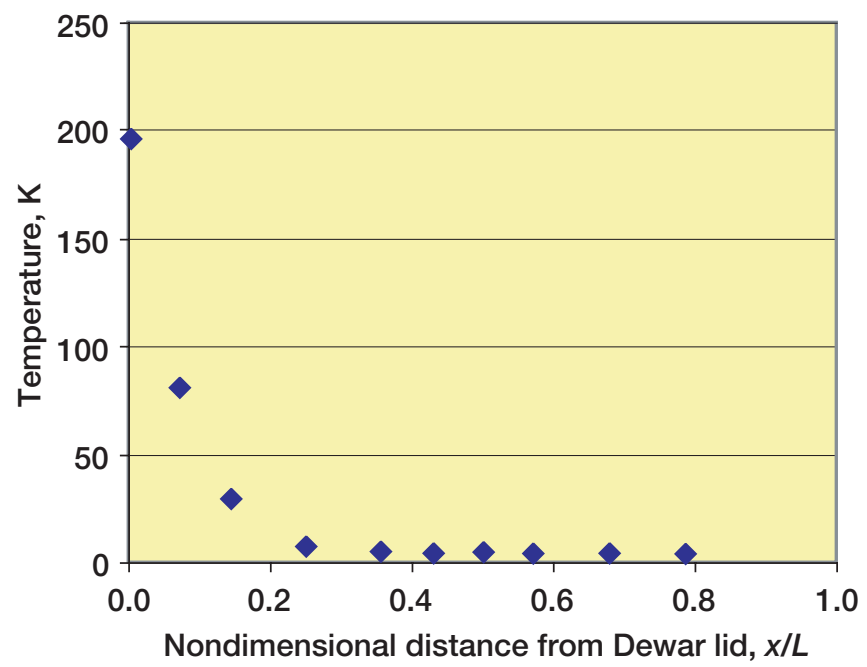

Figure 4.-Temperature distribution in helium Dewar in Feb. 28, 2001, experiments. Distance of helium free surface from Dewar lid is $x$ and length of Dewar, $L$.

The Phase II temperature profile in the helium Dewar is presented in figure 4 . The diodes have a temperature accuracy of $\pm 1 \mathrm{~K}$, and they are attached to a nonmetallic rake composed of circuit board material that extended from the Dewar lid into the liquid helium. The diodes were mounted on the rake. Circuit board material was used as it had a low thermal conductivity, was readily available, and was easily cut to the proper dimensions. A polycarbonate screw attached the top end of the circuit board material to a polycarbonate rod. The upper end of the polycarbonate rod was threaded and screwed into the underside of the helium Dewar lid.

\section{Experimental Procedure}

During the experimental runs, a small amount of liquid hydrogen was dropped onto the surface of the liquid helium. The hydrogen flow rate selected was $1 / 500$ liter/s $\left(4.24 \times 10^{-3} \mathrm{scfm}\right)$ for a run time of 1 to $4 \mathrm{~s}$. This flow rate was selected by comparing the total heat capacity of the hydrogen versus the helium. Selecting a high flow rate would create a very high helium vaporization rate and loss of the liquid helium. With the low flow rate, the particles formation is clearly observed, and it eliminates any chance of the 
relatively warm liquid hydrogen vaporizing all of the liquid helium in the Dewar. Only a small amount of the liquid helium contained in the Dewar vaporized as the hydrogen particles were frozen.

In the first step of the hydrogen freezing process, the liquid hydrogen was subcooled to 14 to $18 \mathrm{~K}$, near its freezing point, by reducing the pressure. By reducing the pressure, the temperature of the liquid hydrogen was reduced. This process allowed the hydrogen to be at a very low temperature, near its freezing point. Comparisons of the heat capacity of helium and the heats of liquefaction and fusion (solidification) of hydrogen led to the selection of conditioning the hydrogen to a very low temperature before releasing it onto the helium surface. Otherwise a large amount of helium would have been used to condense the gaseous hydrogen, liquefy it, and then finally freeze the hydrogen into solid particles. Large clouds of vapor that are created during the longer runs would have also obscured the formation process and thwarted efforts to see the final particles. After the hydrogen particles freeze, they are observed for many minutes.

\section{Test Apparatus Improvements}

The 2001 testing included a number of improvements to the experimental apparatus used in 1999. The lighting in the Dewar was improved with a high-intensity light and a silvered cone to reflect light into spaces that were shadowed in the earlier tests. The mass flow into and out of the Dewar is shown conceptually in figure 5. The gas composition of the venting gases from the Dewar was measured with increased accuracy with the addition of a residual gas analyzer (RGA). A heat exchanger was fabricated and added to the gas space above the liquid helium. Using liquid hydrogen as a coolant, the heat exchanger was designed to help reduce the temperature of the gas above the liquid surface. The insulation and cooling of the precision hydrogen valve was improved. A more reliable operation of the valve was needed to assure the proper small amount of hydrogen was introduced into the Dewar.

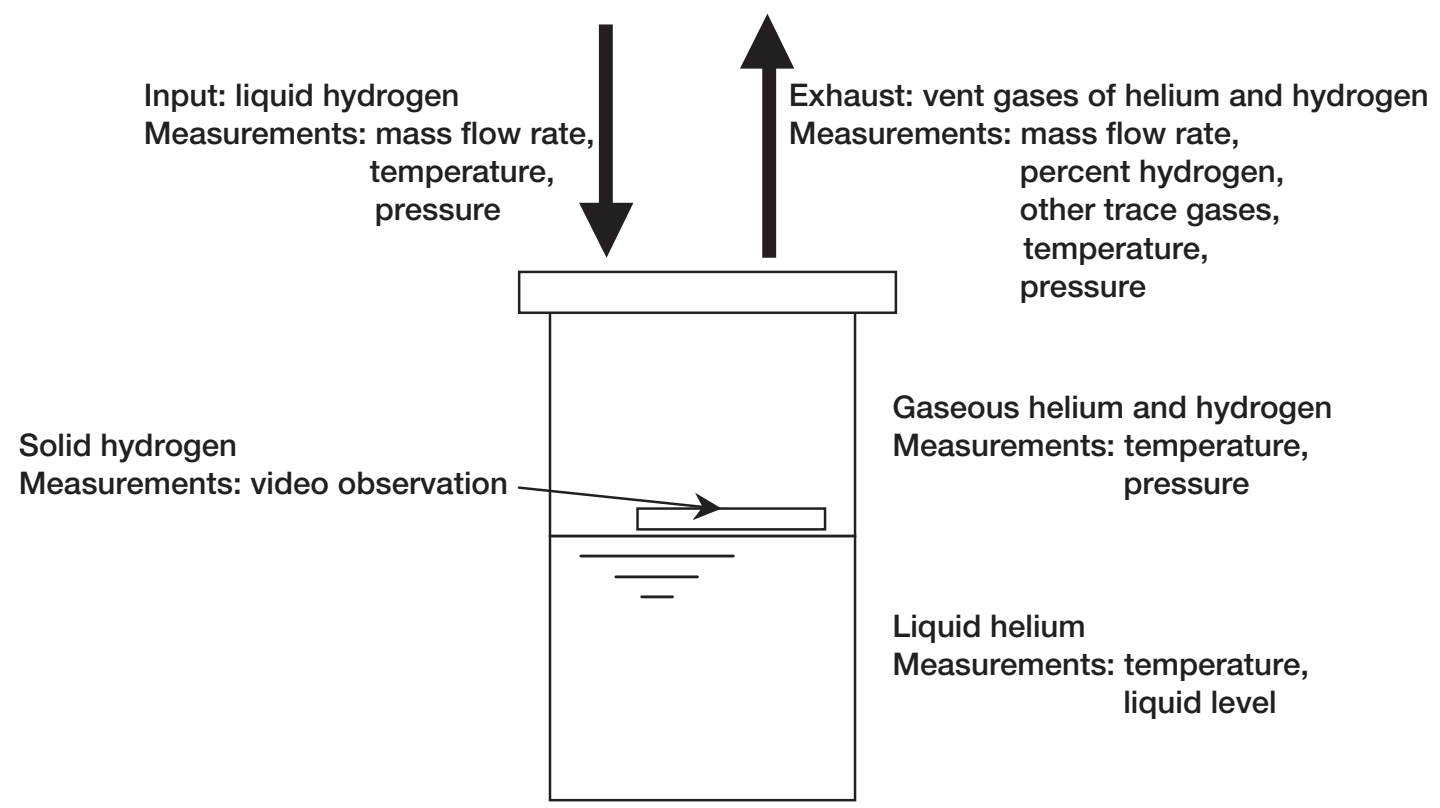

Figure 5.-Experimental measurements made in testing. 
Many more runs were conducted in the 2001 testing. Appendix A provides the list of runs for each of the 11 days of testing. The experience in the 1999 testing allowed for a much greater frequency of testing, and the new operational changes to the experimental apparatus provided more repeatable and reliable flow of the liquid hydrogen.

\section{Experimental Considerations}

As the liquid hydrogen fell toward the helium surface, it became frozen and particles formed immediately after hitting the helium surface. Some of the hydrogen froze as it fell, but some vaporized as well. The hydrogen was a jet of fluid: The outer shear layer vaporized, but the central core remained liquid for a short time, finally freezing during the drop and as it hit the helium surface. Figure 4 provides the temperature profile in the Dewar during the experimental run. It is clear that due to the 50 to $200 \mathrm{~K}$ temperatures above the liquid helium surface, some hydrogen vaporization is likely to occur.

Small clouds of hydrogen were seen forming about the stream of hydrogen falling onto the free surface. Additional mass flow rate instrumentation was included to assess the total mass of hydrogen in the gas phase versus the solid particles. The temperature profiles of the Dewar will shed light on the amount of gas formed, and a thermal and mass balance analysis can be conducted to more accurately measure the distribution of gaseous and solid hydrogen in the Dewar. A mass spectrometer was also used to determine the mass of hydrogen in the helium gas above the liquid helium. The RGA instrument showed that the outflow gases from the Dewar were highly concentrated (95 to 98 percent) in hydrogen.

Solid hydrogen is less dense than liquid helium, so the hydrogen particles floated on the surface, simplifying the particle imaging. In an operational propulsion system, this buoyancy property will be overcome by gelling the helium, thus allowing the hydrogen particles to be suspended in the helium. During these tests, it was noted that the frozen hydrogen particles may also serve as an effective gelling agent for liquid helium (refs. 9 to 11 ).

Many frames from the videotape of the experiment were captured and analyzed. Table II summarizes the timing for the experimental runs, where each solid hydrogen formation run began. There was an interval of between 25 and $65 \mathrm{~min}$ between runs. These time spans were chosen to allow the particles to agglomerate, and to observe any unusual or unexpected properties. A more detailed listing of the events from each run are provided in appendix B. Appendix C and figure 6 show typical images from the testing. The small particles were allowed to float on the helium surface for at least $25 \mathrm{~min}$ before adding more hydrogen. During that 25-min minimum time span, they began to seek each other out, agglomerate into a larger collection of particles, and minimize their surface energy as they float on the helium. The particles also turned from clear or translucent crystals to cloudy crystals, implying a transition from face-centered cubic (FCC) to hexagonal close-packed (HCP) molecule packing (ref. 13). After allowing the first batch of particles to form, the Dewar pressure was lowered to agitate the liquid helium surface, and the particles quickly broke up into their original smaller components. The particles would then again begin to agglomerate when the agitation stopped.

Table II.-Solid hydrogen video event timing, ${ }^{\mathrm{a}}$ Feb. 28, 2001

[Helium level is between 14 and 16 in. below lid during run.]

First drop begins ............................................... 14:50:59:14

Second drop begins ...................................... 16:00:21:17

${ }^{\mathrm{a}}$ Times given as hh:mm:ss:fr, where fr is frame number. 


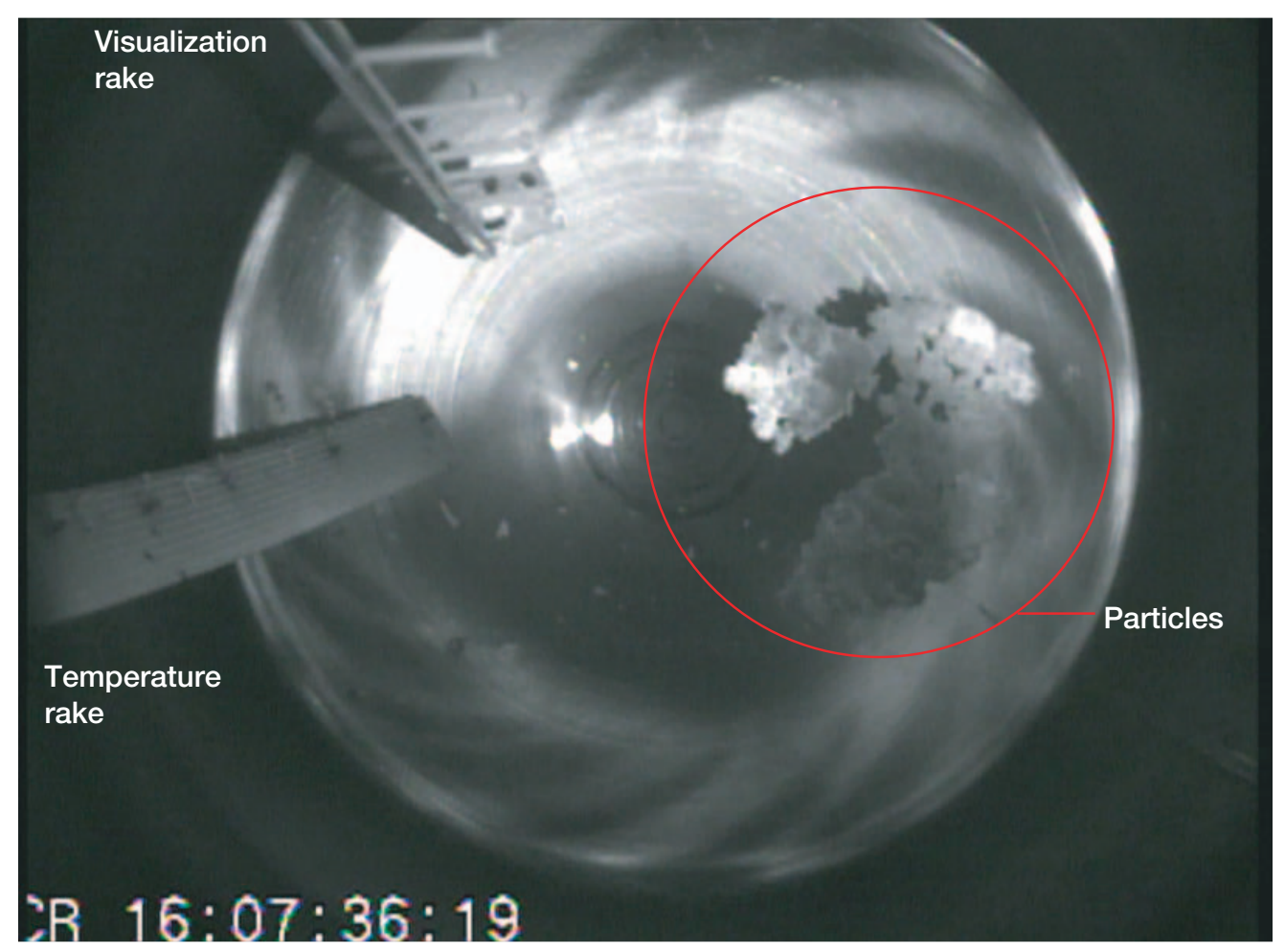

Figure 6.-Image of solid hydrogen image (enclosed in circle), 2001. Full mass on helium surface, 0.3159-m-diameter Dewar.

\section{Solid Hydrogen Testing Results}

Three major observations resulted from these solid hydrogen particle runs: particle sizes, the flows into and out of the Dewar, and the particle formation. Additional observations were made of the thermal profile and stratification in the helium Dewar.

\section{Analysis Background}

The images were taken with a 0.5 -in.-lens, charged-coupled device (CCD) black and white camera. The illumination in the Dewar was created with $150 \mathrm{~W}$ bulb with the light introduced into the Dewar with an optical fiber system. All of the observations were done with a black and white video camera, with a $56^{\circ} \mathrm{FOV}$. The video images were recorded on Betacam and VHS tape formats. The Betacam recordings were used to obtain better high-definition frames for analysis. To analyze the particles, a commercially available photographic manipulation and analysis software package was used.

There was one effective height to the liquid level that were used in the image analyses. In order to assure the entire free surface of the helium could be visualized, the runs were begun with a helium distance $x$ of $355.6 \mathrm{~mm}$ (14 in.) from the Dewar lid $(x / L=0.5)$. The specific particle sizes were then estimated, using the algorithm in the following section. 


\section{Particle sizes}

The solid hydrogen particles were analyzed by digitizing the video images, and measuring the sizes of the particles. The particle size measurements were corrected for the actual size of the particles using the equation

$$
(\text { area, particle })=\frac{(\text { area, Dewar })}{(\text { pixels, Dewar })}(\text { pixels, particle })
$$

where

area, particle is the area of the particle $\left(\mathrm{mm}^{2}\right)$

area, Dewar is the area of the Dewar free surface $\left(\mathrm{mm}^{2}\right)$

pixels, Dewar is the number of pixels in the imaged free surface

pixels, particle is the number of pixels in the imaged particle

At the beginning of and during each run, a variety of individual particles are measured. The smallest of the particles is identified, as well as a representative set of other larger particle sizes. Figure 6 illustrates a typical image from the analyses. The circle encompasses a small set of hydrogen particles that have agglomerated. The size of the observed particles is limited by the captured image resolution. Once the videotape is captured, it is digitized and image analysis software is used to determine the particle sizes. It is therefore possible that the image analyses may be unable to detect particles smaller than 1 pixel.

Appendix B contains written video observations from the 2001 testing, and appendix C provides the 2001 video image data. These data are the raw measurements of the particle sizes from the video observations. Appendix D contains the particle sizes in tabular data format.

In the Phase II tests of February 28, 2001, small particles were formed during the initial freezing process. However, the smallest particles were formed many minutes after the initial freezing of the hydrogen. Observations inside the Dewar showed that hydrogen did freeze on the Dewar walls and finally came to rest on the liquid helium surface; this phenomenon is the likely cause of the late-forming hydrogen particles. This observation is distinctly different from the 1999 freezing experiments, where no such very small particles were seen. Figure 7 provides data from the February 28, 2001 tests. The figure shows the particle sizes at the start of the first run, how the particle size changes when the surface is agitated, and how the size changes again after the addition of more hydrogen at the start of the second run. The smallest particle sizes are 1.50 to $2.08 \mathrm{~mm}$ (0.06 to $0.08 \mathrm{in}$.). In these tests, no control was placed on the particle formation other than the temperature and pressure of the helium and hydrogen and the flow rate of the hydrogen. The simple freezing process is somewhat random, and the particles will vary in size simply because of the random breakup of the stream of hydrogen that fell onto the helium during the freezing process. The other measurement variation of the particles from the video images was due to all of the particles not being perfectly spherical or elliptical; thus an average size was measured. The 2001 testing included some unique observations, such as tiny scintillating particles curling up in strings to form larger millimeter-sized particles. 


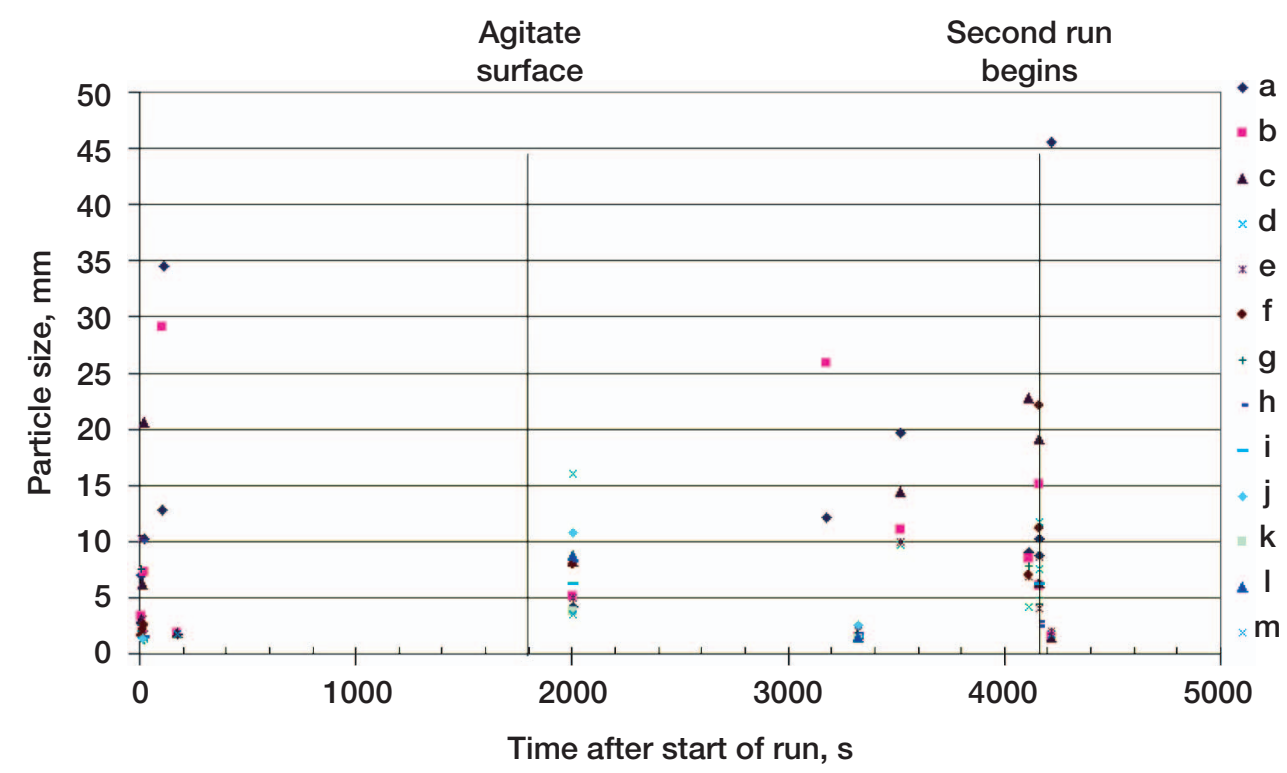

Figure 7.-Solid hydrogen particle sizes versus time, Feb. 28, 2001.

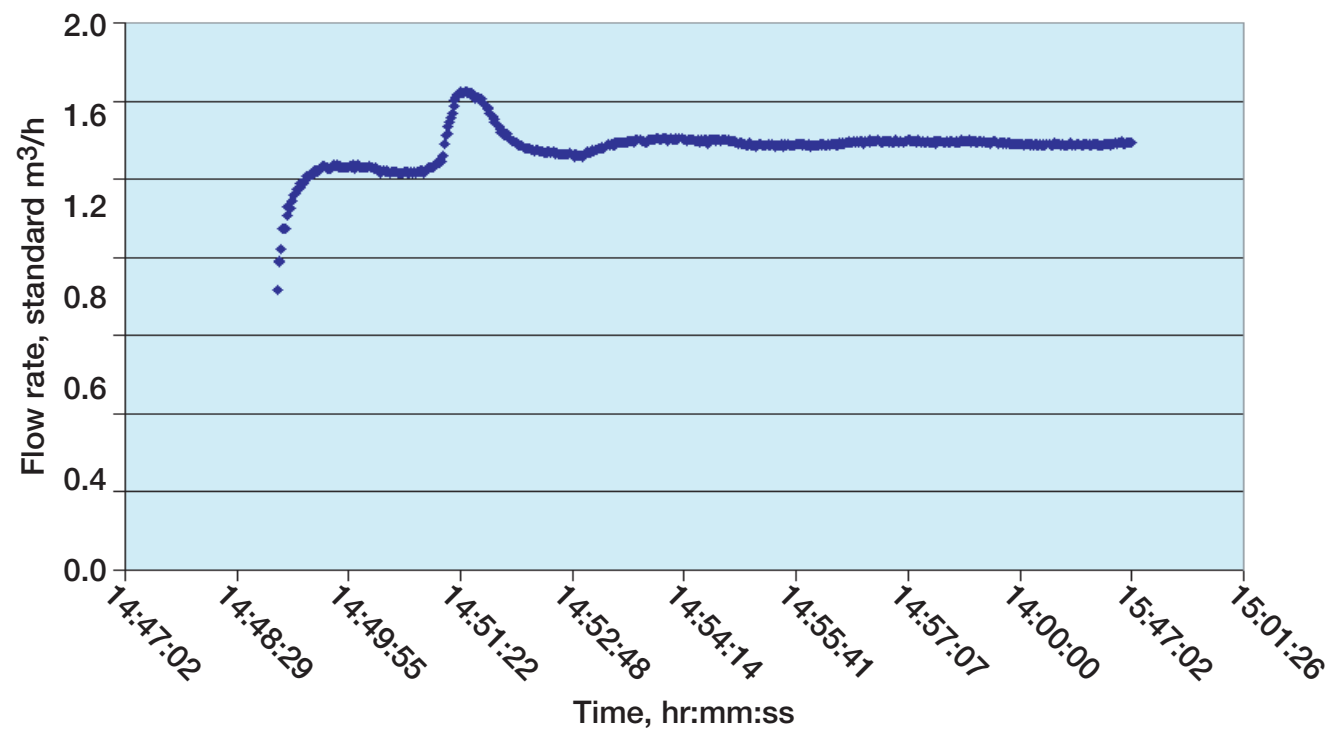

Figure 8.-Gaseous hydrogen flow rate out of Dewar, Feb. 28, 2001. Valve FH127 used.

\section{Flow Out of Dewar}

The flow meter at the exit of the Dewar exhaust stack records the volumetric flow rate out of the Dewar. Figure 8 shows a flow rate versus time plot for a 1-s run (representing a hydrogen flow time of $1 \mathrm{~s}$ ) on February 28, 2001. Figure 9 provides similar data for the 2-s run of February 27. The total outflow mass for the two runs is quite different and is dependent upon the Dewar gas temperature and the conditions for each run.

The time for the flow rate to reach equilibrium on the first run of February 28 was about $1 \mathrm{~min}$. The view on the camera however shows that the view remains clear with the February 28 run, and is partially obscured by clouds of hydrogen for 13 min with the February 27 run. The temperature in the helium 


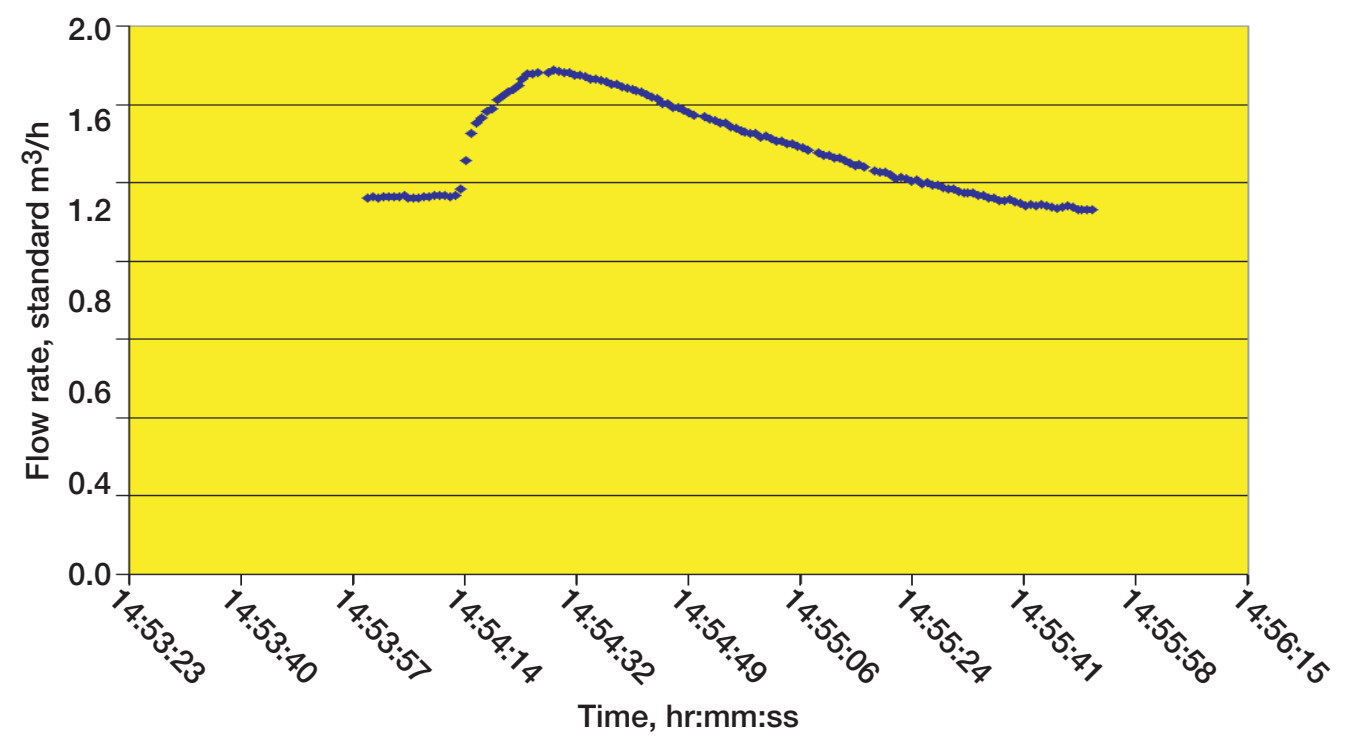

Figure 9.-Gaseous hydrogen flow rate out of Dewar, Feb. 27, 2001.

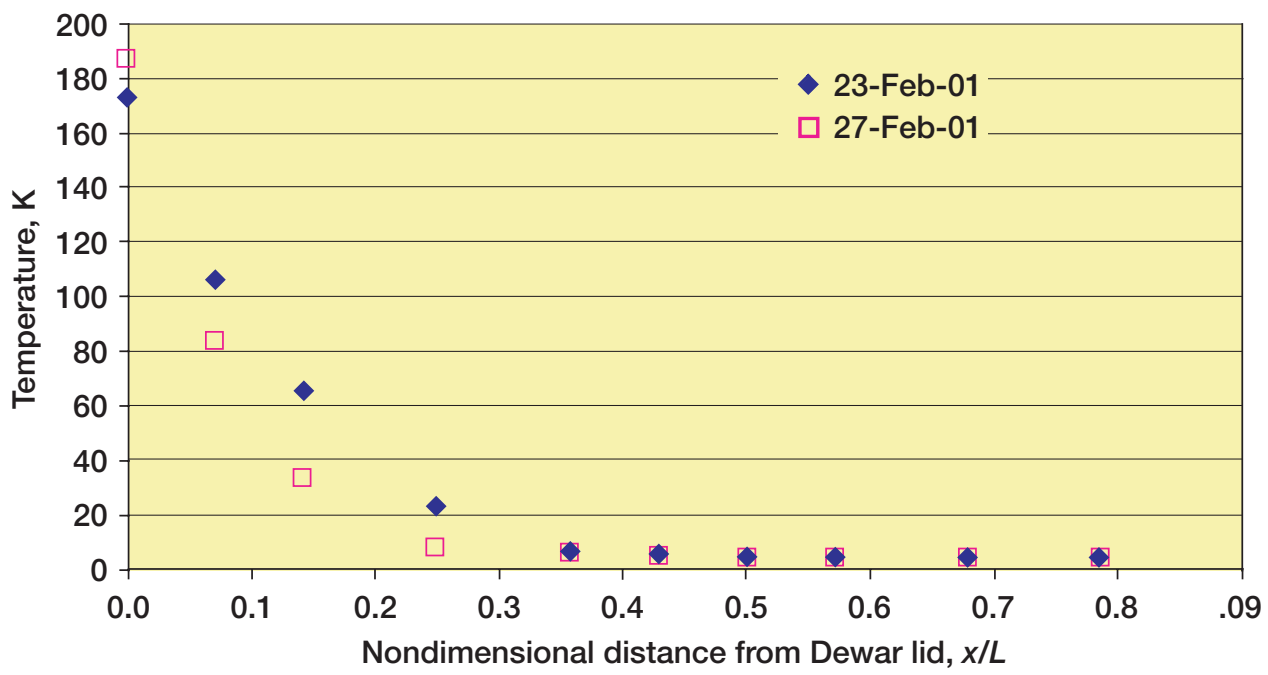

Figure 10.-Temperature distribution in helium Dewar during hydrogen drop, Feb. 23 and 27, 2001. Distance of helium free surface from Dewar lid is $x$ and length of Dewar, $L$.

Dewar for the February 28 run is shown in figure 4. The Dewar liquid and gas temperature was generally lower in the run on February 28 than in the runs on February 27. The data for the contrasting earlier runs is provided in figure 10 .

\section{Flow Into Dewar}

During the range of runs conducted in the 2001 Phase II test, the mass flow rate of liquid hydrogen into the Dewar is maintained for 1 to $3 \mathrm{~s}$. The nominal flow rate desired was approximately $1 / 500$ or $1 / 100$ liter/s $\left(4.24 \times 10^{-3}\right.$ or $\left.2.12 \times 10^{-2} \mathrm{scfm}\right)$. These flow rates correspond to the precision flow valve being 


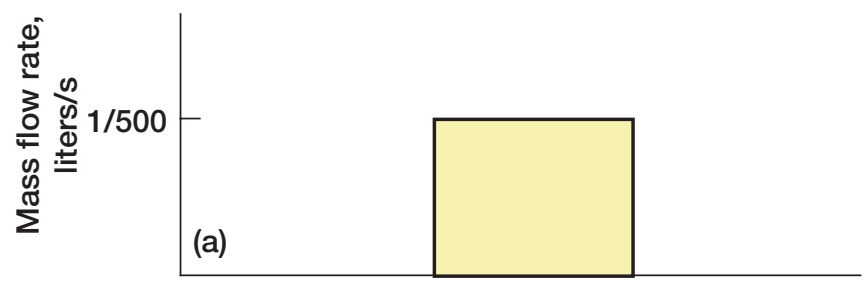

Time, s

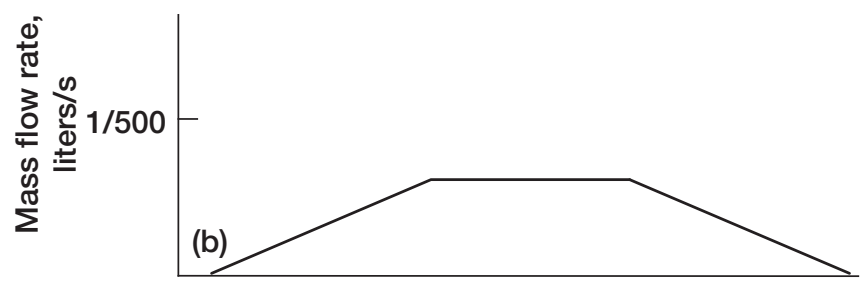

Time, s

Figure 11.-Notional liquid hydrogen mass flow rate for solid hydrogen tests, 2001. (a) Theoretical. (b) Experimental planned.

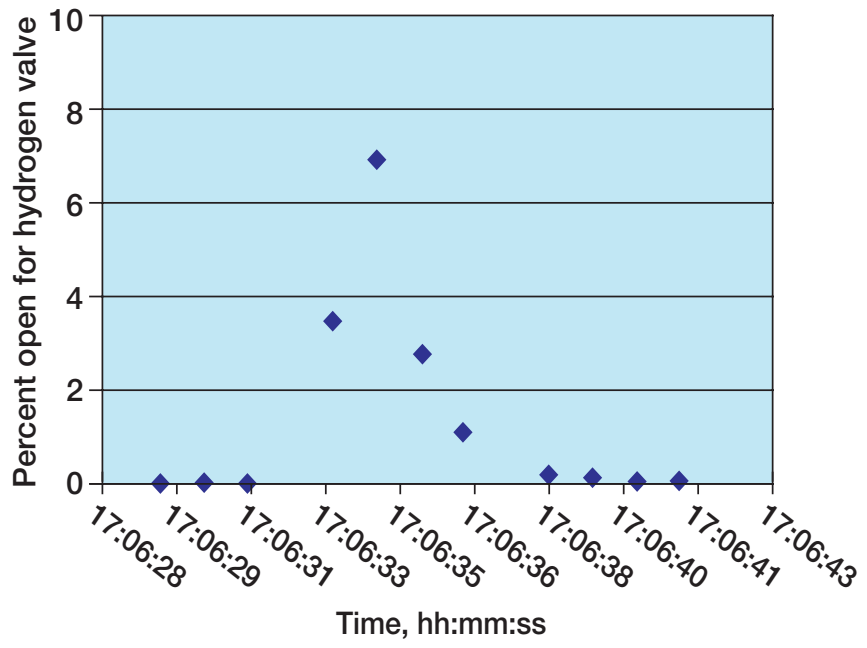

Figure 12.-Liquid hydrogen valve opening percentage versus time for hydrogen flow rate into Dewar, Feb. 28, 2001. Valve FHA01_1 used.

15 and 30 percent open, respectively. Based on the calibration of the precision control flow valve, the flow rate is not linear, but somewhat sharply peaked. Figure 11 shows the notional comparison of the theoretically desired mass flow rate and the rate physically possible with the apparatus. Figure 12 depicts the typical valve percent open data from the liquid hydrogen valve, and it is related to actual flow rate from the test configuration. The instantaneous flow rate is therefore significantly different than the planned rate, and this difference led to better planning for conducting the experiments. Essentially, the integrated mass flow of the hydrogen was compared to the predicted desired mass flow. Accommodations were made for the specific mass flow characteristics of the hydrogen valve to assure a very small controlled hydrogen flow rate. Although average flow rates could not be used, actual total masses of liquid hydrogen flow could be estimated and used in the calculations. 


\section{Timing Event Influence}

During the testing there are several time scales that affect the solid hydrogen formation: The time of flow for the liquid hydrogen, the time for the hydrogen outflow to be completed, and the time for the gas in the ullage to liquefy and then solidify. The flow of liquid hydrogen in the tank is about 1 to $4 \mathrm{~s}$, the time for the outflow to stabilize is about $60 \mathrm{~s}$, and the time for the freezing of the hydrogen gas in the Dewar ullage is about 1 to $30 \mathrm{~min}$.

The flow of liquid hydrogen is controlled by the precision flow rate hydrogen valve and the pressure difference across it. This flow rate is computed using standard techniques. During the testing, care was taken to prevent the hydrogen tank pressure from exceeding the helium Dewar pressure. If the hydrogen tank pressure were not properly controlled, a small amount of unplanned leakage of hydrogen into the helium Dewar would occur, creating particles before an experimental run was planned to begin.

The freezing of the ullage gas was influenced by its temperature and rate of flow into the Dewar. These values can be controlled more rigorously in future experiments, but they were not controlled precisely in the experimental runs presented here.

\section{Comparison of 1999 and 2001 Testing}

There were some interesting similarities and differences between the 1999 and 2001 tests. Figure 13 shows the 1999 particle size results. Overall, the initially formed particles were 1.8 to $4.6 \mathrm{~mm}(0.07$ to 0.18 in.) in diameter. These sizes are very similar to those from 2001: 1.0 to $6.4 \mathrm{~mm}$ (0.04 to $0.25 \mathrm{in}$.). However, numerous smaller particles were observed in the February 28, 2001, tests.

Particle compaction was found in this set of experimental runs, as with the Phase I tests in 1999. The compaction trends seen in the Phase I and II testing were similar. The smallest particle sizes were very small (almost microscopic) in most cases, and much smaller than those seen in Phase I. The lower Dewar temperatures were able to freeze particles onto the walls of the Dewar, and these particles flow down the walls and enter the liquid helium.

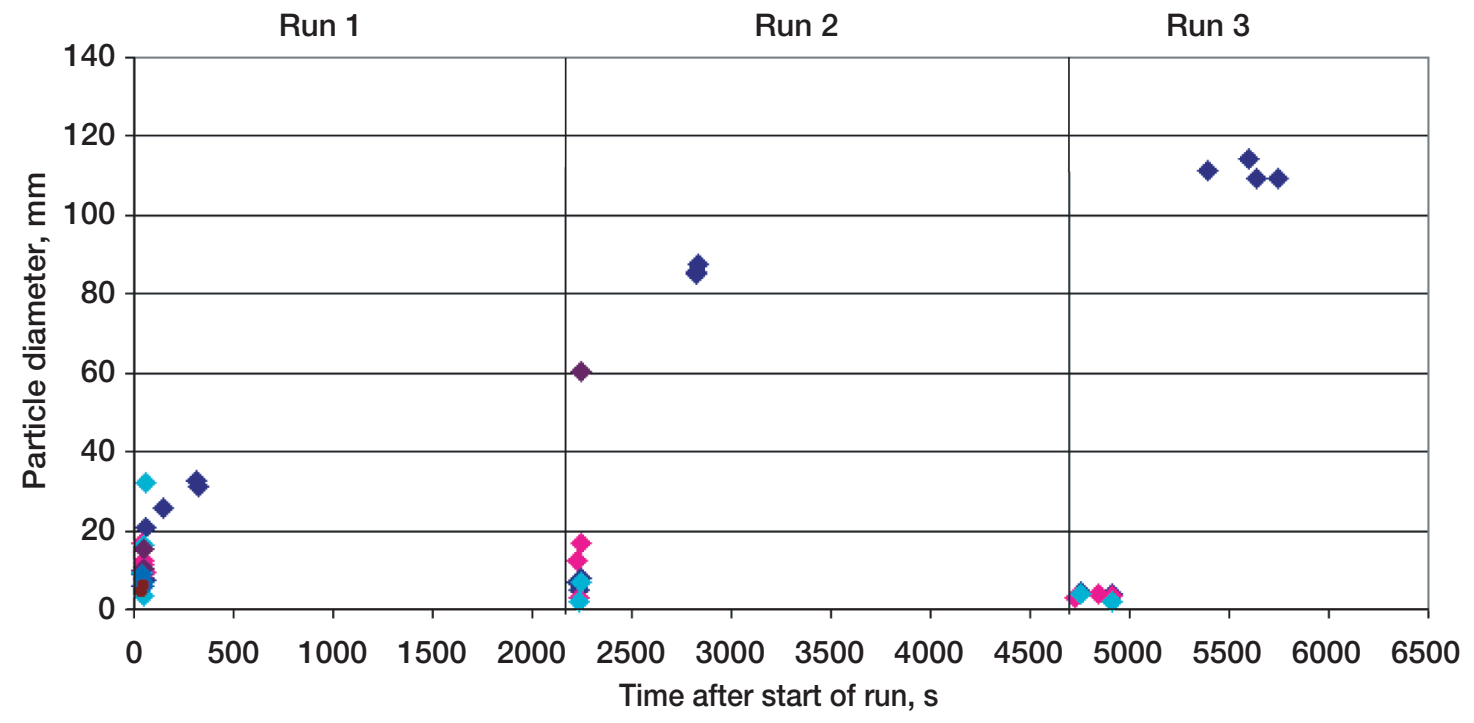

Figure 13.-Solid hydrogen particle sizes versus time, 1999 tests. 
Many additional images and other temperature data are available for analyses, and these additional images and data can give more insights into the formation process. Initial analyses of the video and flow rate data showed many new phenomena that were not previously observed. These phenomena include the formation of what appear to be microscopic hydrogen particles, the formation of long coiled structures of hydrogen that curl up to form small particles, and the formation of long bars of solid hydrogen. Additional data and video analyses will show the precise conditions under which the new phenomena occur.

\section{Conclusions}

The solid hydrogen testing described in this paper was the Phase II testing of a program to characterize solid hydrogen particles. The improvements to the test article allowed a better measurement of the hydrogen flow rate into and out of the Dewar. These measurements allowed the computation of a production efficiency in the earlier analyses of the Phase II tests and showed that the formation efficiency is related to many aspects of the event timing for the experiment.

The particle sizes formed in the Phase I (1999) and the Phase II (2001) testing were of very similar sizes. In the Phase I (1999) tests, the sizes ranged from 1.8 to $4.6 \mathrm{~mm}(0.07$ to $0.18 \mathrm{in}$.) in diameter. The Phase II tests of February 23 and 27, 2001, produced particle sizes of 1.0 to $6.4 \mathrm{~mm}(0.04$ to 0.25 in.). The testing analyzed in this paper (Feb. 28, 2001 tests) produced numerous tiny particles in the range of 1.50 to $2.08 \mathrm{~mm}$ (0.06 to $0.08 \mathrm{in}$.) in size. These tiny particles were also observed with other phenomena, which included the presence of microscopic scintillating particles. These tiny and microscopic particles appear to form from hydrogen that froze onto the Dewar walls and slid into the liquid helium.

\section{Concluding Remarks}

The data analyzed thus far shows that the formation process must happen slowly to allow for the most efficient solid hydrogen particle formation. A fast flow will create a large cloud of hydrogen, much of which will go out of the vent stack. Additional data analyses will reveal the best flow rates for future experiments.

Future propulsion systems using atomic rocket propellants with solid hydrogen will likely require massive facilities for creating particles and many complex processes to trap atoms. Though the complexities seem daunting, the potential of these propellants is great, and the capacity for reducing vehicle lift-off weight and increasing payload capacity is theoretically unmatched. In some future vehicles and energy systems, atomic propellants in solid hydrogen may allow us to store and controllably release large quantities of energy, and allow the final human expansion into the solar system.

\section{References}

1. Palaszewski, B.: Launch Vehicle Performance for Bipropellant Propulsion Using Atomic Propellants With Oxygen. AIAA 99-2837, 1999.

2. Palaszewski, B.: Launch Vehicle Performance With Solid Particle Feed Systems for Atomic Propellants. AIAA 98-3736 (NASA/TM-1998-208498), 1998.

3. Palaszewski, B.: Solid Hydrogen Testing and Analyses for Atomic Rocket Propulsion. Paper presented to the Propulsion Engineering Research Center (PERC) 11th Annual Symposium on Propulsion, State College, PA, 1999.

4. Palaszewski, B.: Atomic Propellants for Aerospace Propulsion Systems: Solid Hydrogen Experiments and Vehicle Analyses. Paper presented at the 1999 USAF High Energy Density Materials Contractors Conference, Cocoa Beach, FL, 1999. 
5. Palaszewski, B.: Atomic Hydrogen as a Launch Vehicle Propellant. AIAA 90-0715 (NASA TM-102459), 1990.

6. Lubell, M.; Lue, J.; and Palaszewski, B.: Large-Bore Superconducting Magnets for High Energy Density Propellant Storage. Paper presented at the 1996 Applied Superconductivity Conference, Pittsburgh, PA, 1996.

7. Palaszewski, B.; Ianovski, L.; and Carrick, P.: Propellant Technologies: Far Reaching Benefits for Aeronautical and Space Vehicle Propulsion. AIAA J. Propul. Pow., 1998, pp. 641-648.

8. Palaszewski, B.: Atomic Hydrogen Propellants: Historical Perspectives and Future Possibilities. AIAA 93-0244 (NASA TM-106053), 1993.

9. Palaszewski, B.: Solid Hydrogen Experiments for Atomic Propellants. AIAA 2000-3855, 2000.

10. Palaszewski, B.: Solid Hydrogen Experiments for Atomic Propellants: Image Analyses. AIAA 2001-3233, 2001.

11. Palaszewski, B.: Solid Hydrogen Experiments for Atomic Propellants: Particle Formation Energy and Imaging Analyses. AIAA 2002-4092, 2002.

12. Dempsey, P.; and Stochl, R.: Supplemental Multilayer Insulation Research Facility. NASA TM-106991, 1995.

13. Silvera, I.: The Solid Molecular Hydrogens in the Condensed Phase: Fundamentals and Static Properties. Reviews of Modern Physics, vol. 52, no. 2, pt. I, 1980, pp. 393-452.

14. McCarty, R.D.: Hydrogen Technology Survey: Thermophysical Properties. NASA SP-3089, 1975.

15. Fajardo, Mario: Personal communication, USAF Research Laboratory, Edwards, CA, July 1999.

16. Sanger, E.: Rocket Flight Engineering. NASA Technical Translation TTF223 (from "Raketenflugtechnik" Verlag Von Oldenburg, Berlin, 1965).

17. McNellis, N., et al.: A Summary of the Slush Hydrogen Technology Program for the National AeroSpace Plane. NASA TM-106863 (AIAA Paper 95-6056), 1995.

18. Hardy, T.L.: FLUSH: A Tool for the Design of Slush Hydrogen Flow Systems. NASA TM-102467, 1990.

19. Sater, J.D.; Pipes, J.; and Collins, G.W.: Cryogenic D-T Fuel Layers Formed in 1-mm Spheres By Beta-Layering. Lawrence Livermore National Laboratory Report Number UCRL-JC-128031-ABSREV-1, 1998.

20. Collins, G.W., et al.: Forming Uniform D-T and D2 Layers for Cryogenic NIF Targets. Lawrence Livermore National Laboratory Report Number UCRL-JC-129969-ABS, 1998.

21. Bittner, D.N.: Forming Uniform HD Layers in Shells Using Infrared Radiation. Lawrence Livermore National Laboratory Report Number UCRL-JC-131371, 1998.

22. Collins, G.W., et al.: Forming and Smoothing D2 and HD Layers for ICF By Infrared Heating. Lawrence Livermore National Laboratory Report Number UCRL-JC-123596-ABS, 1996.

23. Collins, G.W.: Reducing DT Surface Roughness for Cryogenic Ignition Targets. Lawrence Livermore National Laboratory Report Number UCRL-C-124884-ABS, 1996.

24. Kozioziemski, B.J.; Collins, G.W.; and Bernat, T.P.: Single Crystal Growth of Solid D2. Lawrence Livermore National Laboratory Report Number UCRL-JC-125981-ABS, 1997.

25. Kozioziemski, B.J., et al.: Crystal Growth and Roughening of Solid D2. Fusion Technol., (Lawrence Livermore National Laboratory Report Number UCRL-JC-125121-ABS), vol. 31, 1997, pp. 482-484.

26. Bittner, D.N., et al.: Generation of Uniform Solid HD Layers Inside Spherical Capsules Using Infrared Illumination. Lawrence Livermore National Laboratory Report Number UCRL-JC-125140-ABS, 1996.

27. Bernat, T.P., et al.: Heat-Flux Induced Changes to Multicrystalline D2 Surfaces. Lawrence Livermore National Laboratory Report Number UCRL-JC-124261-ABS-REV-1, 1997.

28. Kozioziemski, B.J.; Collins, G.W.; and Bernat, T.P.: D2 Crystal Growth and Surface Energy. Lawrence Livermore National Laboratory Report Number UCRL-JC-130037-ABS, 1998. 
29. Fajardo, M.: Cryosolid Propellants-The Last "Revolutionary" HEDM Concept. Proceedings of the High Energy Density Matter (HEDM) Contractors Conference, Scientific Special, M. Berman, ed., 2000.

30. Larson, C.W.: Kinetics of Boron Carbon HEDM. Proceedings of the High Energy Density Matter (HEDM) Contractors Conference, Scientific Special, M. Berman, ed., 2000.

31. Talroze, V.L., et al.: Measurement of the Hyperfine State of the Hydrogen Atom as it Interacts in the Gas Phase With CO, SO2, CO2, and N2O Molecules. Akademiia Nauk SSSR, Doklady, vol. 227, 1976, pp. 407-410.

32. Gordon, E.B., et al.: Change in the Hyperfine State of the Hydrogen Atom During Its Collisions With Unsaturated Hydrocarbon Molecules in the Gaseous State. Soviet Physics-JETP, vol. 36, no. 2, 1973, pp. 212-215. Translation. (Previously cited in Zhurnal Eksperimental'noi i Teoreticheskoi Fiziki, vol. 36, no. 2, 1973, pp. 401-406.)

33. Hardy, W.N., et al.: Optical Phonons in Solid Hydrogen and Deuterium in the Ordered State. Phys. Rev. Letters, vol. 21, no. 5, 1968, pp. 291-294.

34. Agosta, C.C., et al.: Trapping of Neutral Atoms With Resonant Microwave Radiation. Phys. Rev. Lett., vol. 62, no. 20, 1989 pp. 2361-2364.

35. Stoof, Henk T.C.: Few-Body Collisions in a Weakly Interacting Bose Gas. Ph.D. Thesis, Technische Universiteit Eindhoven, 1989. 


\section{Appendix A-Liquid Hydrogen Flow Rate-Related Data for Solid Hydrogen Testing in 2001}

Hydrogen flow valve-on time and experiment timing from the 2001 tests are presented in the table below:

\begin{tabular}{|c|c|c|c|c|}
\hline Date: & $\begin{array}{l}\text { Number } \\
\text { of runs }\end{array}$ & & $\begin{array}{l}\text { or runs start } \\
\text { nate, hh:mm:ss) } \\
\text { ole, hh:mm:ss:fr) }\end{array}$ & $\begin{array}{l}\text { Mass flow rate, } \mathrm{H} 2 \\
\text { (\% open), on-time (s) }\end{array}$ \\
\hline Feb. 23, 2001 & 1 run & 1, & $12: 18: 00$ & $30 \%, 2 \sec \left(1 / 100^{\text {th }}\right.$ liter $\left./ \mathrm{s}\right)$ \\
\hline Feb. 27, 2001 & 1 run & 1 , & $14: 55: 00$ & $30 \%, 2 \sec \left(1 / 100^{\text {th }}\right.$ liter $\left./ \mathrm{s}\right)$ \\
\hline Feb. 28, 2001 & 3 runs & $\begin{array}{l}1, \\
2, \\
3\end{array}$ & $\begin{array}{l}14: 51: 00 \\
16: 00: 35 \\
17: 06: 30\end{array}$ & $\begin{array}{l}15 \%, 1 \sec \left(1 / 500^{\text {th }} l i t e r / s\right) \\
15 \%, 1 \sec \left(1 / 500^{\text {th }} l i t e r / s\right) \\
15 \%, 1 \sec \left(1 / 500^{\text {th }} l \text { liter } / \mathrm{s}\right)\end{array}$ \\
\hline March 1, 2001 & 3 runs & $\begin{array}{l}1, \\
2, \\
3\end{array}$ & $\begin{array}{l}13: 29: 00 \\
14: 58: 00 \\
16: 19: 30\end{array}$ & $\begin{array}{l}15 \%, 1 \sec \left(1 / 500^{\text {th }} \text { liter } / \mathrm{s}\right) \\
15 \%, 1 \sec \left(1 / 500^{\text {th }} \operatorname{liter} / \mathrm{s}\right) \\
15 \%, 1 \sec \left(1 / 500^{\text {th }} \text { liter } / \mathrm{s}\right)\end{array}$ \\
\hline March 9, 2001 & 2 runs & 2 & $\begin{array}{l}12: 40: 00 \\
\text { (approx.) } \\
14: 13: 00\end{array}$ & $15 \%, 1 \sec \left(1 / 500^{\text {th }}\right.$ liter $\left./ \mathrm{s}\right)$ \\
\hline March 12, 2001 & 3 runs & $\begin{array}{l}1, \\
2, \\
3\end{array}$ & $\begin{array}{l}12: 16: 00 \\
14: 16: 00 \\
15: 52: 00\end{array}$ & $\begin{array}{l}15 \%, 2 \sec \left(1 / 500^{\text {h }} \text { liter } / \mathrm{s}\right) \\
15 \%, 3 \sec \left(1 / 500^{\text {th }} l \text { liter } / \mathrm{s}\right) \\
15 \%, 4 \sec \left(1 / 500^{\text {th }} l i t e r / s\right)\end{array}$ \\
\hline March 26, 2001 & 3 runs & $\begin{array}{l}1, \\
2, \\
3\end{array}$ & $\begin{array}{l}14: 24: 00 \\
15: 27: 00 \\
16: 10: 00\end{array}$ & $\begin{array}{l}15 \%, 1 \sec \left(1 / 500^{\text {th }} \text { liter } / \mathrm{s}\right) \\
15 \%, 2 \sec \left(1 / 500^{\text {th }} \text { liter } / \mathrm{s}\right) \\
15 \%, 1 \sec \left(1 / 500^{\mathrm{h}} \text { liter } / \mathrm{s}\right)\end{array}$ \\
\hline March 27, 2001 & 5 runs & $\begin{array}{l}1, \\
2, \\
3, \\
4, \\
5\end{array}$ & $\begin{array}{l}11: 36: 00 \\
12: 41: 00 \\
13: 26: 00 \\
14: 43: 00 \\
15: 44: 00\end{array}$ & $\begin{array}{l}15 \%, 3 \sec \left(1 / 500^{\text {th }} \operatorname{liter} / \mathrm{s}\right) \\
15 \%, 2 \sec \left(1 / 500^{\text {th }} \operatorname{liter} / \mathrm{s}\right) \\
15 \%, 2 \sec \left(1 / 500^{\text {th }} \operatorname{liter} / \mathrm{s}\right) \\
15 \%, 3 \sec \left(1 / 500^{\text {th }} \operatorname{liter} / \mathrm{s}\right) \\
15 \%, 4 \sec \left(1 / 500^{\text {th }} \operatorname{liter} / \mathrm{s}\right)\end{array}$ \\
\hline March 28, 2001 & 4 runs & $\begin{array}{l}1, \\
2, \\
3, \\
4,\end{array}$ & $\begin{array}{l}12: 57: 00 \\
14: 01: 00 \\
14: 34: 00 \\
15: 47: 00\end{array}$ & $\begin{array}{l}15 \%, 4 \sec \left(1 / 500^{\text {th }} \text { liter } / \mathrm{s}\right) \\
15 \%, 3 \sec \left(1 / 500^{\text {th }} l i t e r / s\right) \\
15 \%, 3 \sec \left(1 / 500^{\text {th }} l i t e r / s\right) \\
15 \%, 1 \sec \left(1 / 500^{\text {th }} l i t e r / s\right)\end{array}$ \\
\hline March 29, 2001 & 3 runs & $\begin{array}{l}1, \\
2, \\
3,\end{array}$ & $\begin{array}{l}12: 27: 00 \\
13: 27: 00 \\
14: 26: 00\end{array}$ & $\begin{array}{l}15 \%, 4 \sec \left(1 / 500^{\text {th }} \text { liter } / \mathrm{s}\right) \\
15 \%, 1 \sec \left(1 / 500^{\text {th }} \text { liter } / \mathrm{s}\right) \\
15 \%, 1 \sec \left(1 / 500^{\text {th }} \text { liter } / \mathrm{s}\right)\end{array}$ \\
\hline April 2, 2001 & 7 runs & $\begin{array}{l}1, \\
2, \\
3, \\
4, \\
5, \\
6, \\
7,\end{array}$ & $\begin{array}{l}11: 42: 00 \\
12: 55: 00 \\
13: 40: 00 \\
14: 20: 00 \\
15: 09: 00 \\
16: 09: 00 \\
16: 44: 00\end{array}$ & $\begin{array}{l}15 \%, 1 \sec \left(1 / 500^{\text {th }} \text { liter } / \mathrm{s}\right) \\
15 \%, 1 \sec \left(1 / 500^{\text {th }} \text { liter } / \mathrm{s}\right) \\
15 \%, 1 \sec \left(1 / 500^{\text {th }} \text { liter } / \mathrm{s}\right) \\
15 \%, 1 \sec \left(1 / 500^{\text {th }} \text { liter } / \mathrm{s}\right) \\
15 \%, 1 \sec \left(1 / 500^{\text {th }} \text { liter } / \mathrm{s}\right) \\
15 \%, 1 \sec \left(1 / 500^{\text {th }} \text { liter } / \mathrm{s}\right) \\
15 \%, 1 \sec (?)\left(1 / 500^{\text {th }} \text { liter } / \mathrm{s}\right)\end{array}$ \\
\hline
\end{tabular}




\section{PAGE INTENTIONALLY LEFT BLANK}

$-18-$ 


\section{Appendix B-Solid Hydrogen Video Observations: February 28, 2001}

The following lines present the observations recorded during two solid hydrogen formation runs on February 28, 2001:

February 28, 2001: Run 1

14:16:00 Begin $\mathrm{H}_{2}$ tank filling

14:41:00 Preparing to drop $\mathrm{H}_{2}$

14:47:4:01 Beginning of taping

14:50:59:14 Run 1 begins. Drop $\mathrm{H}_{2}$ onto helium surface, very clear, with little vapor created. Mass flow rate $=1 / 500^{\text {th }}$ liter per second, for 1 second

14:51:00:19 Particles are visible. View is clear, no clouds present

14:51:04:23 Particle are moving

14:51:04:26 Good image for "smallest" particles

14:51:15:10 Also, good image for small particles

14:51:19:06 Massive number of small tiny particles

14:51:25:02 Swarms... tiny particles. Height in the Dewar is 14 to 16 inches, below the Dewar lid.

14:52:44:06 Good image of agglomerate. Swarms still persist.

14:52:50:17 Good agglomerate image

14:53:54:06 Tiny particle image (good for image capturing)

14: 55:49:00 Hydrogen agglomerate trapped at visualization rake

14:56:26:00 Good image of hydrogen agglomerate for area calculation

14:56:55:06 Also, good image for area analysis

15:05:23:12 Particles have not yet agglomerated. Surface is somewhat dynamic!

15:06:57:18 Hydrogen agglomerate breaks up into many smaller pieces. They are about 0.5 to 0.75 inches in diameter

15:09:45:11 Lots of motion on the surface, with many smaller agglomerates

15:10:31:03 No tiny particles noticed

15:16:06:23 Particles (hydrogen agglomerates) still not agglomerating fully. Agglomerates seem to be compacting over time. 
15:17:36:17 Good image for area measurement, with 4 or 5 masses present

15:17:35:29 Good image for area analysis

15:18:10:19 Hydrogen agglomerate continues to break up, and re-agglomerate.

15:23:23:02 Pressure reduced in Dewar, particles (agglomerates) are agitated.

15:23:27:03 Good edge, field of view (FOV) shot (bottom left of image)

15:23:27:15 Another good edge, FOV shot (bottom left of image)

15:23:30:01 FOV is clear

15:23:30:02 Good edge, FOV shot, near the top left of the image.

15:24:05:21 FOV shot, good edge (center right edge)

15:24:23:02 Small, tiny particles are observed, in the center of the FOV.

15:26:25:10 Particles, and small agglomerates, are dispersed over the entire surface

15:29:47:28 Helium surface is very quiescent

15:32:25:12 Many tiny particles are visible again, mostly at the center of the FOV

15:34:57:13 Tiny particles persist, almost all particles seem to repel each other with some electrostatic charge.

Thought (or observation): Particle freeze onto the wall of the Dewar, slide down creating a charge on the particle. Probably a whimsical thought.

15:36:21:07 Many more tiny particle visible

15:39:50:03 Most of the particle agglomerate

15:43:17:14 End of tape 1. Particles still persist in motion, changing shape and configuration

Tape 2:

15:43:42:09 Beginning of Tape 2

15:44:00:06 Good image for area measurement

15:46:19:21 Boiling occurring at the temperature rake

15:49:38:26 Particle flies off the Dewar wall, onto the helium surface. It departs from the left center of the image.

15:50:28:13 Boiling occurring at the temperature rake, cloudy surface beginning. 
15:53:02:24 Particles hover and stick to the visualization rake.

15:57:22:19 Particles still not fully agglomerated

15:59:34:02 Good image for area calculation. There are seven particles and /or agglomerates

16:00:21:17 Solid hydrogen formation - Run 2 of the day begins. One can see the particles forming. Mass flow rate $=1 / 500^{\text {th }}$ liter per second, for 1 second

16:00:21:21 New small particles form, about 1/16 inch in diameter (they appear dark at formation).

16:00:22:16 Larger particles appear (about 1/8 inch in diameter)

16:00:24:08 New particle mix with "old" ones (ones from the previous run)

16:00:36:00 It is quite cloudy at the top of the FOV

16:01:17:16 Good image of "complete" large agglomerate. Tiny particles are swarming.

16:01:46:08 Many tiny particles attach to the larger mass (or agglomerate).

16:02:54:16 The agglomerate is stabilizing on the visualization rake, and there are still many tiny particles grabbing onto the main agglomerate.

16:03:24:23 Fog clearing at the top of the FOV

16:04:35:08 Micro-particles swirl incessantly, in a boiling frenzy

16:05:27:07 Very good image for image capturing. There are still many micro-particles.

16:05:40:06 Very good image for image capturing.

16:06:08:10 Agglomerate breaks away from the visualization rake.

16:06:45:10 Agglomerate rotates, elements reconfigure themselves. Location is near the visualization rake.

16:07:00:03 Only a small number of micro-particles are visible.

16:07:38:04 Agglomerate pulsates.

16:08:06:03 Visible darkening or aging of the agglomerate

16:08:41:20 Small particles appear, as if from out of nowhere.

16:08:46:11 Particles collide, and stick to the agglomerate

16:09:42:09 Agglomerate lazily moves about the visualization rake

16:09:57:07 Small waves appear on the surface, and the image is very clear. 
16:11:21:14 Good image for image capturing.

16:11:58:10 A 'smile' appear in the solid hydrogen. The agglomerate takes on the vague structure of a Cleveland Indians "Chief Wahoo."

16:12:51:22 Quiet surface

16:17:17:01 Agglomerate moves lazily about the visualization rake

16:22:21:02 Reduce the Dewar pressure to agitate particles

16:22:25:07 Edge of the FOV is evident (near the upper left of the image)

16:22:26:05 Agitation completed. Pressure is restored. Dozens of small and intermediate particles are visible. Good image for capturing.

16:22:33:14 Particles are very numerous, and moving about. Most seem to be 10's of millimeter in diameter.

16:23:21:19 Particles are moving rhythmically across the helium surface and beginning to reagglomerate.

16:23:51:06 Small millimeter-sized particles are evident. Good image for capturing.

16:24:31:00 No swarms of tiny particles are present. Surface calming down.

16:26:04:21 The particles (large ones) cluster at the bottom and top of the FOV.

16:29:45:19 Bali dancer persist from the agitation. There appears to be a waving hand in the center of the FOV.

16:31:00:18 Many small particles reappear (they are millimeter sized and smaller).

16:31:22:09 Strings appear. They are likely to be long chains of solid hydrogen micro-particles.

16:31:33:23 An amorphous, diaphanous mass appears, near and above the center of the FOV.

16:34:20:01 Good image for image capturing.

16:34:48:28: More diaphanous sheets appear. They are above the center of the FOV and to the bottom right of the center of the FOV.

16:35:17:05 Most of the particles are 'hiding' behind the visualization rake.

16:35:36:11 Good image for detecting small particles.

16:37:45:16 Agglomerate is nearly complete. It begins rotating on the visualization rake.

16:38:42:05 Good image for image capturing.

16:39:09:24 GREAT image - capture it! Agglomerate is free of the visualization rake. 
16:39:52:08 Another clear view

16:43:40:19 Agglomerate continues rotation, with small (!) agglomerate at each rake.

16:44:19:24 Smaller agglomerate from the temperature rake breaks free.

16:44:50:00 Great agglomerate image

16:47:54:00 End of Tape 2. 


\section{Appendix C-Solid Hydrogen Images}

The following images show video observations recorded during the solid hydrogen testing on February 28, 2001. The images correspond to timing observations in appendix B.
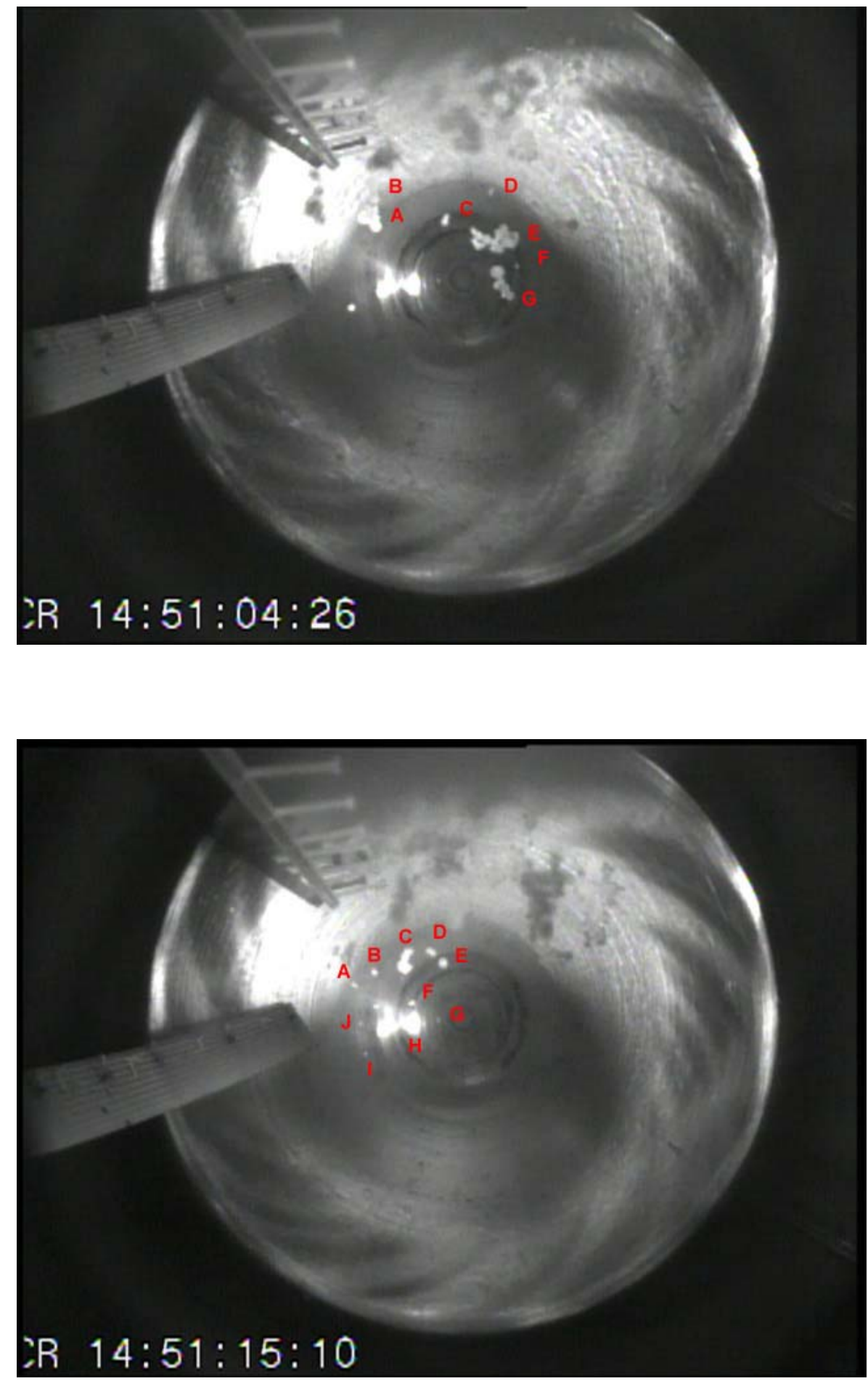

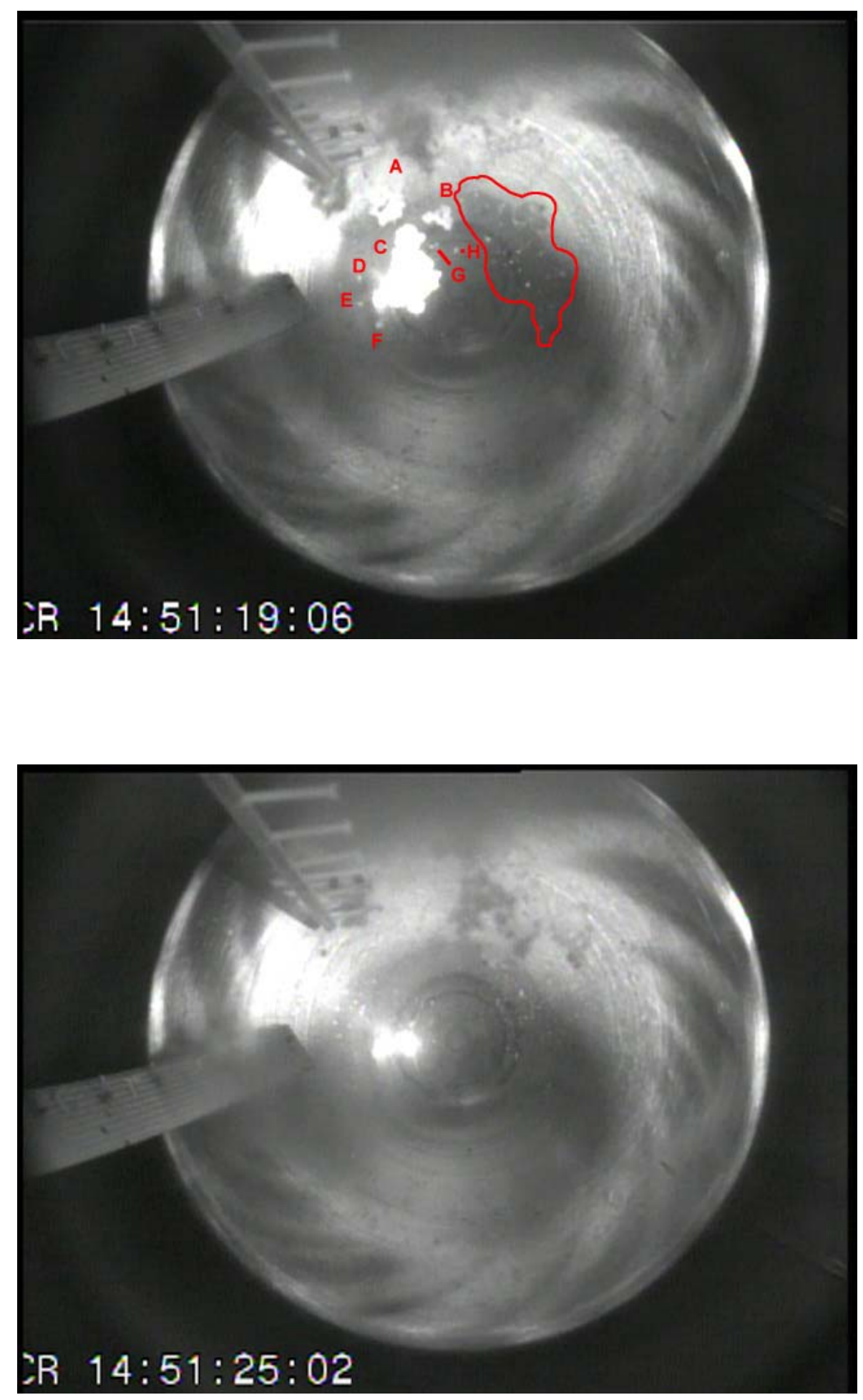

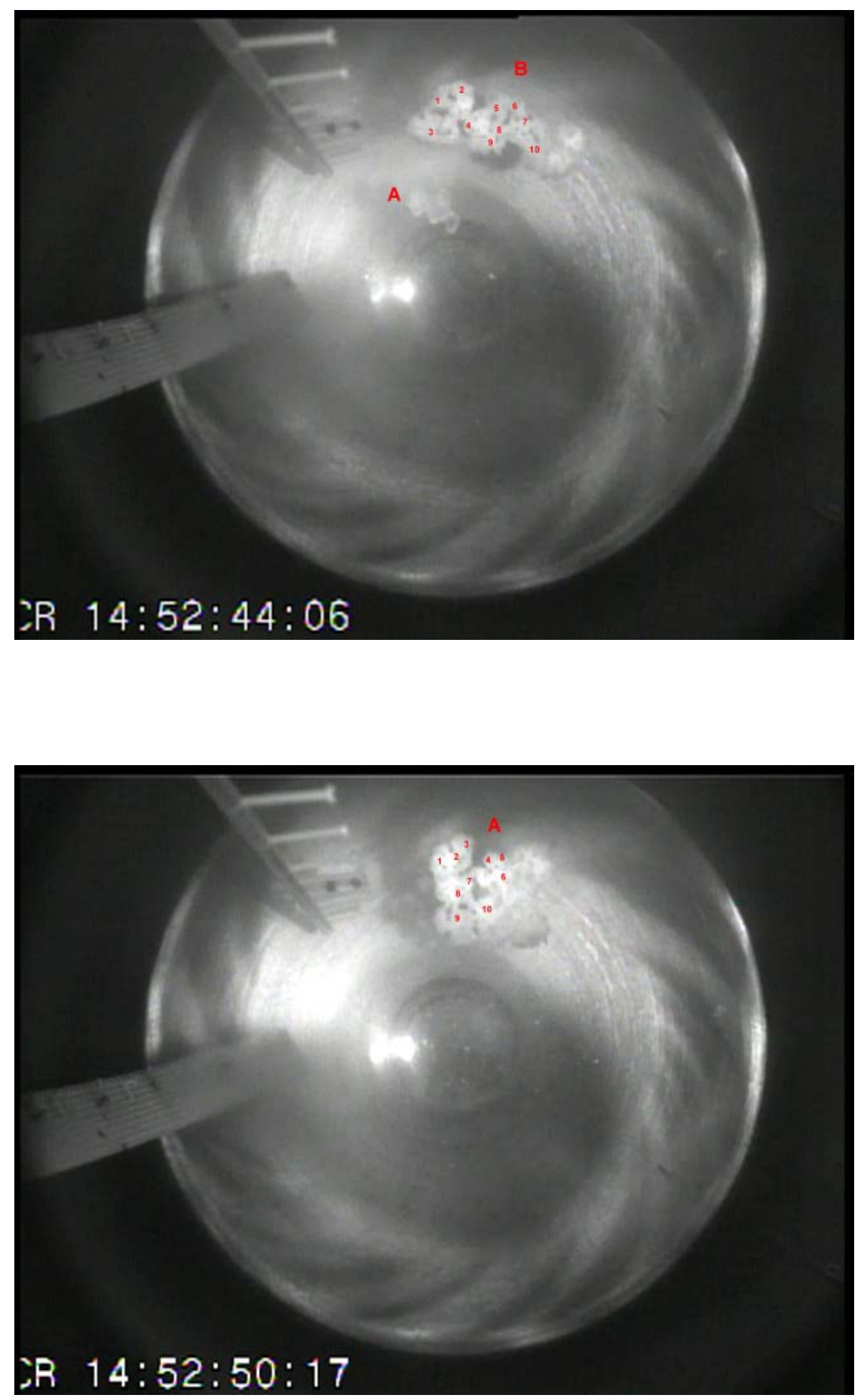

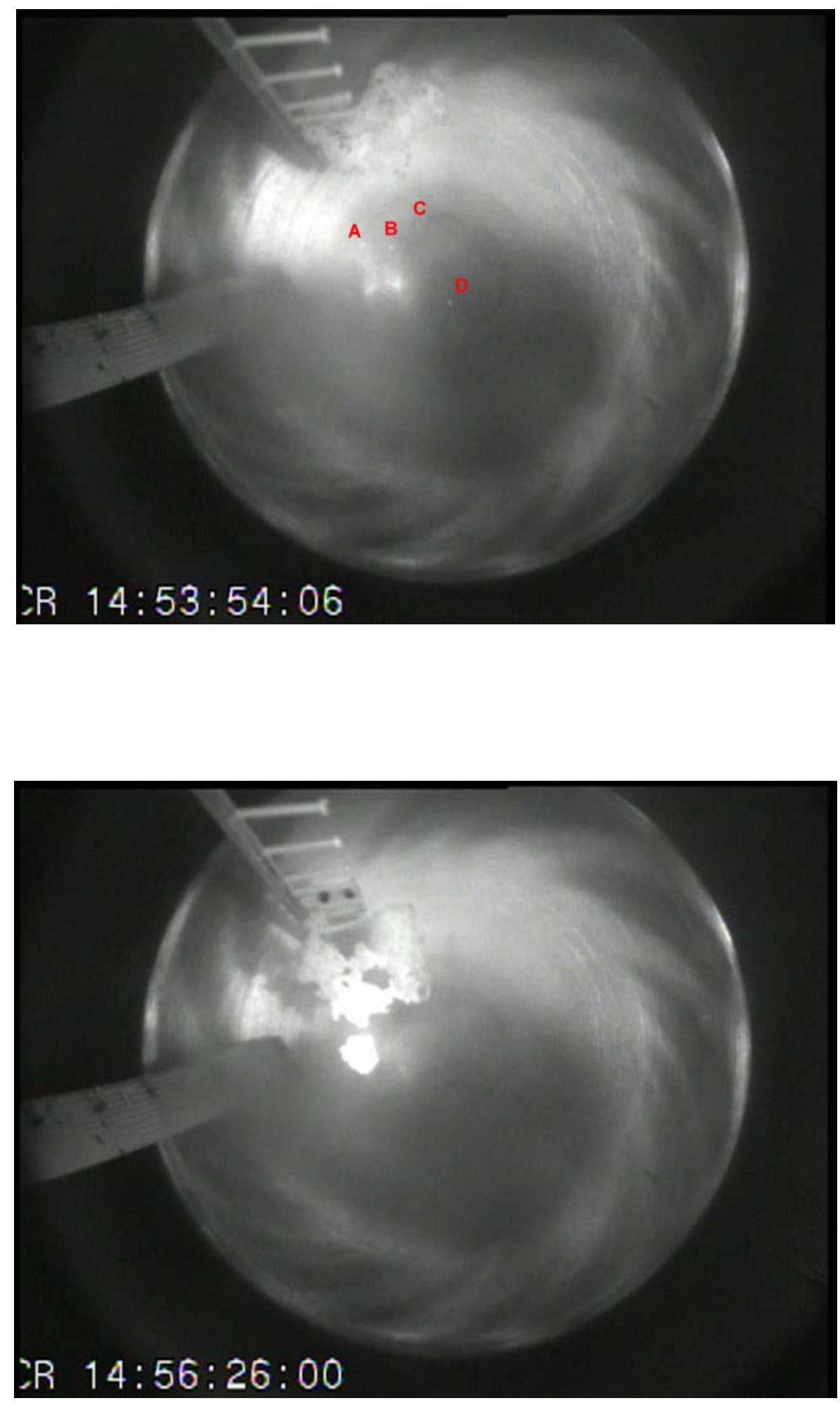


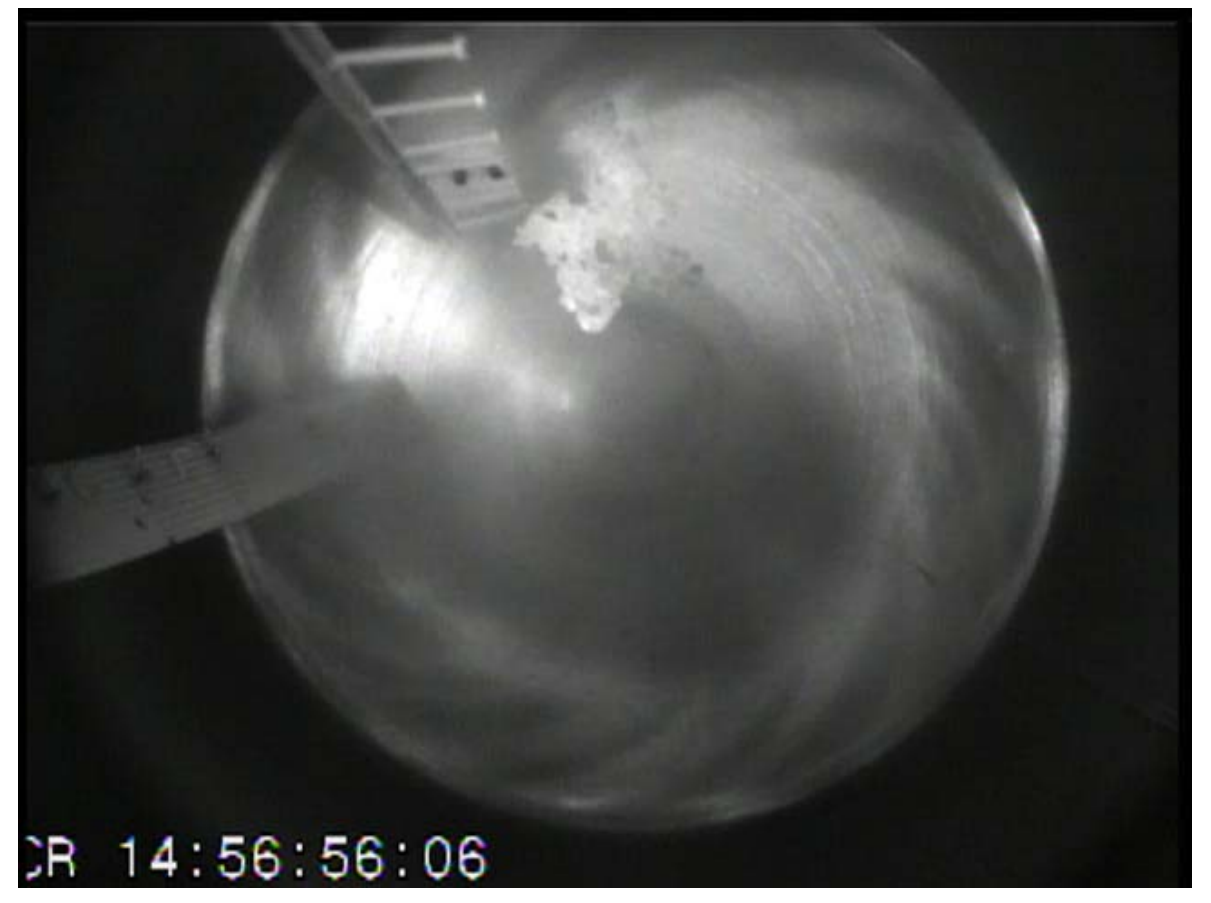




\section{Appendix D—Solid Hydrogen Particle Sizes}

The following table presents the solid hydrogen particle sizes obtained from video observations of the two runs described in appendix B made on February 28, 2001.

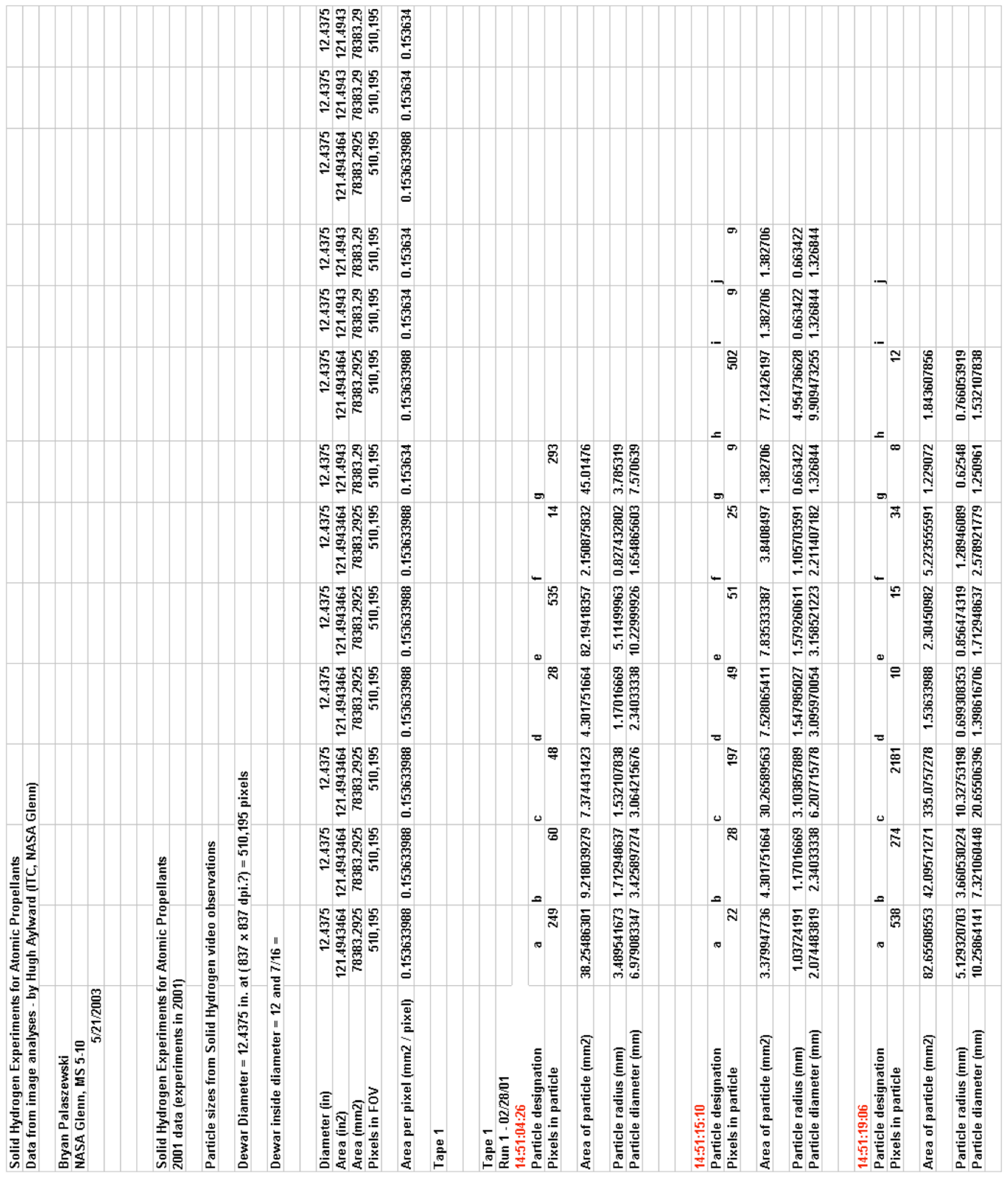




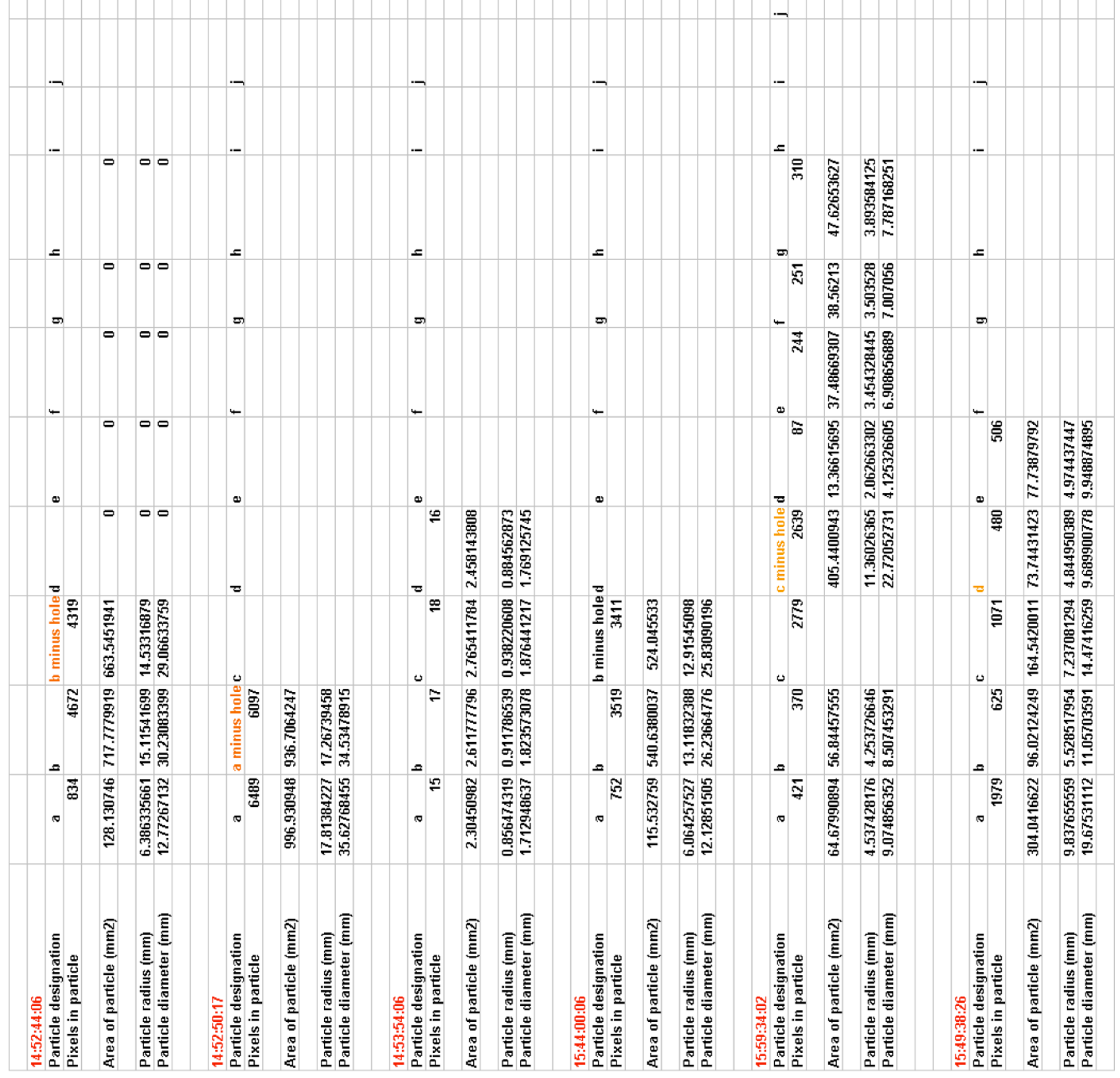




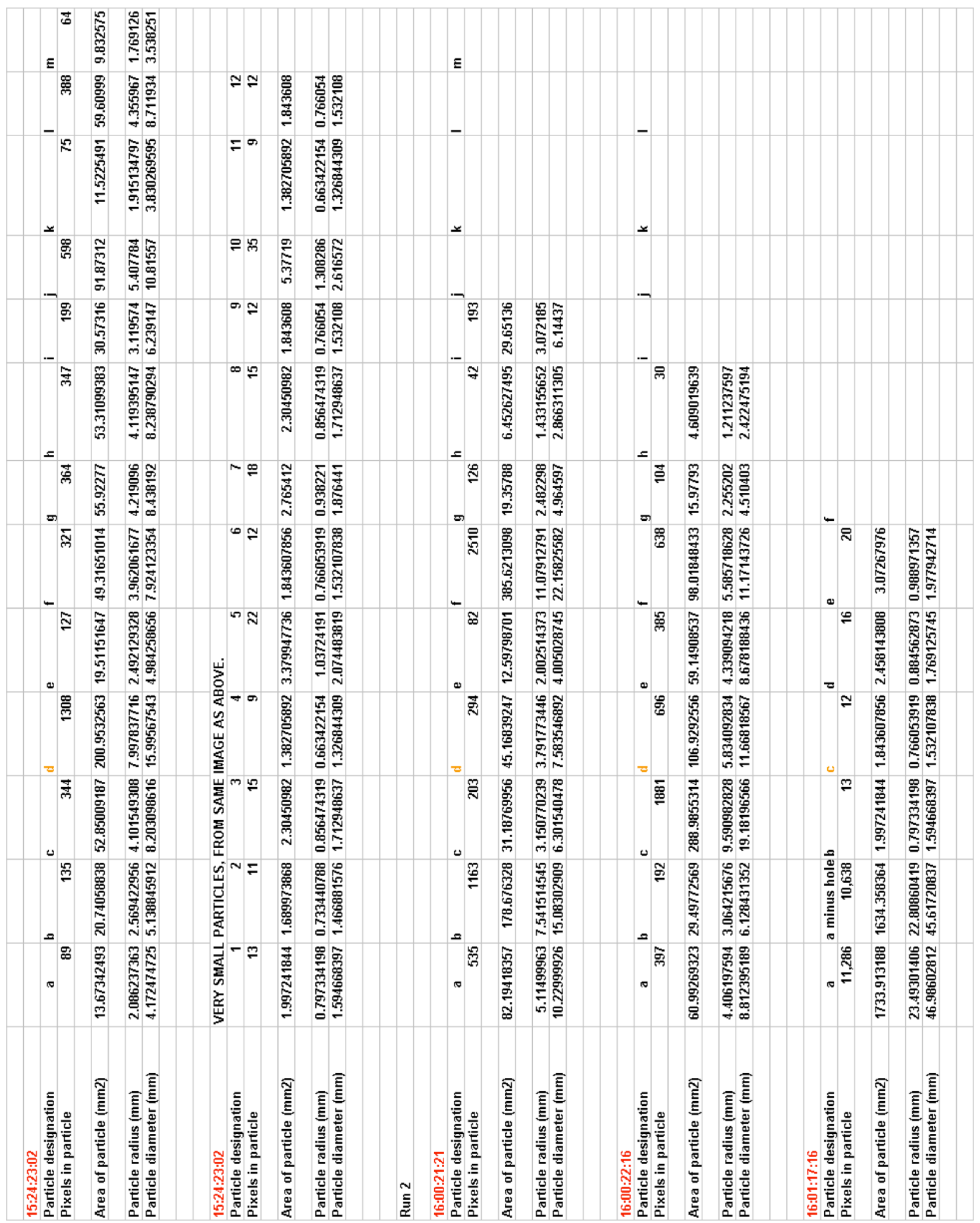


Public reporting burden for this collection of information is estimated to average 1 hour per response, including the time for reviewing instructions, searching existing data sources, gathering and maintaining the data needed, and completing and reviewing the collection of information. Send comments regarding this burden estimate or any other aspect of this collection of information, including suggestions for reducing this burden, to Washington Headquarters Services, Directorate for Information Operations and Reports, 1215 Jefferson Davis Highway, Suite 1204, Arlington, VA 22202-4302, and to the Office of Management and Budget, Paperwork Reduction Project (0704-0188), Washington, DC 20503.

\begin{tabular}{|l|l|l}
\hline 1. AGENCY USE ONLY (Leave blank) & $\begin{array}{c}\text { 2. REPORT DATE } \\
\text { November } 2005\end{array}$ & $\begin{array}{r}\text { 3. REPORT TYPE AND DATES COVERED } \\
\text { Technical Memorandum }\end{array}$
\end{tabular}

4. TITLE AND SUBTITLE 5. FUNDING NUMBERS

Solid Hydrogen Experiments for Atomic Propellants: Particle Formation, Imaging, Observations, and Analyses

6. AUTHOR(S)

Bryan Palaszewski

7. PERFORMING ORGANIZATION NAME(S) AND ADDRESS(ES)

National Aeronautics and Space Administration

John H. Glenn Research Center at Lewis Field

Cleveland, Ohio 44135-3191

\section{SPONSORING/MONITORING AGENCY NAME(S) AND ADDRESS(ES)}

National Aeronautics and Space Administration

Washington, DC 20546-0001
8. PERFORMING ORGANIZATION REPORT NUMBER

E-14317

WU- 713-74-10-00

10. SPONSORING/MONITORING AGENCY REPORT NUMBER

NASA TM-2005-212897

AIAA-2003-4688

\section{SUPPLEMENTARY NOTES}

Prepared for the 39th Joint Propulsion Conference and Exhibit cosponsored by the AIAA, ASME, SAE, and ASEE, Huntsville, Alabama, July 20-23, 2003. Responsible person, Bryan Palaszewski, organization code RTB, 216-977-7493.

12a. DISTRIBUTION/AVAILABILITY STATEMENT 12b. DISTRIBUTION CODE

Unclassified - Unlimited

Subject Categories: 15, 16, 20, and 28

Available electronically at http://gltrs.grc.nasa.gov

This publication is available from the NASA Center for AeroSpace Information, 301-621-0390.

\section{ABSTRACT (Maximum 200 words)}

This report presents particle formation observations and detailed analyses of the images from experiments that were conducted on the formation of solid hydrogen particles in liquid helium. Hydrogen was frozen into particles in liquid helium, and observed with a video camera. The solid hydrogen particle sizes and the total mass of hydrogen particles were estimated. These newly analyzed data are from the test series held on February 28, 2001. Particle sizes from previous testing in 1999 and the testing in 2001 were similar. Though the 2001 testing created similar particles sizes, many new particle formation phenomena were observed: microparticles and delayed particle formation. These experiment image analyses are some of the first steps toward visually characterizing these particles, and they allow designers to understand what issues must be addressed in atomic propellant feed system designs for future aerospace vehicles.

\section{SUBJECT TERMS}

Solid hydrogen; Atomic species; Propellants; Feed systems; Gelled; Fuels; Cryogenics

17. SECURITY CLASSIFICATION OF REPORT

Unclassified
18. SECURITY CLASSIFICATION OF THIS PAGE

Unclassified
19. SECURITY CLASSIFICATION OF ABSTRACT

Unclassified
15. NUMBER OF PAGES

36

16. PRICE CODE

20. LIMITATION OF ABSTRACT

Standard Form 298 (Rev. 2-89)

Prescribed by ANSI Std. Z39-18 298-102 

